\title{
Adaptación y rendimiento de 20 clones de camote (Ipomoea batatas L.) de doble propósito en el ecosistema de Bosque Seco, Piura
}

\section{Adaptation and yield of $\mathbf{2 0}$ clones of sweet potato (Ipomoea batatas L.), dual purpose in the Dry Forest ecosystem, Piura}

\author{
Armando Quispe ${ }^{1}$

\section{RESUMEN} \\ Se evaluó la adaptación y rendimiento de 20 clones de camote en diseño BCR/3r donde las UE se di- \\ vidieron en franjas (A) y (B). En (A) se hizo dos cortes de follaje A1 y A2 (75 y 150 días) y en (B) un corte \\ (150 días) junto a la cosecha de raíces. El prendimiento fue 27,5 esquejes estadísticamente similares, las \\ plantas mostraron Regular a Buen Vigor-Uniformidad-Cobertura, y nula a media floración. \\ Los rendimientos de follaje en (A) fluctúan de 93,09 a 41,36 t/ha, destaca DLP-90052 y en (B) de 49,44 \\ a 16,97 t/ha, sobresale DLP-2462. El promedio en (A) es 59,21 t/ha y 30,08 t/ha en (B). Los rendimientos \\ de raíces en (A) varían de 7,30 a 0,00 t/ha, y en (B) de 18,43 a 0,00 t/ha, en ambas destaca Toquecita con la \\ máxima producción, ocho clones no producen raíces reservantes (0,00 t/ha). El promedio de raíces en $(\mathrm{A})$ \\ es 0,94 y $2,20 \mathrm{t} / \mathrm{ha}$ en (B), con altas diferencias estadísticas. El mayor rendimiento de follaje (+97\%) reduce \\ a $43 \%$ el rendimiento de raíces. Las raíces comerciales representan al $65 \%$ y $76 \%$ del total en (A) y (B). \\ Los rendimientos de MS foliar varia de 9,39 a 3,33 t/ha, destaca DLP-2462 y la MS en raíces varia de \\ 4,36 a 0,00 t/ha; destaca Toquecita como el mayor contenido. El contenido de proteína foliar fluctúa de 7,34 \\ a 2,86 t/ha, destacan Helena y DLP-2462 con 7,34 y 6,56 t/ha. La proteína en raíces de Toquecita y Solapa \\ (t) es 1,26 y $0,09 \mathrm{t} / \mathrm{ha}$. \\ La relación Raíz/Follaje (R/F), demuestra que Toquecita tiene aptitud doble propósito y los 20 clones \\ restantes son forrajeras. Nueva tecnología generada de camote doble propósito logra rendimientos de $15 \mathrm{y}$ \\ 16 t/ha de forraje y raíces, R: B/C 1,57 y utilidad S/. 4,083/ha. \\ Palabras clave: Ecosistemas, bosque seco, selección avanzada, doble propósito.
}

\section{ABSTRACT}

Adaptation and leaf and root yield of 20 sweet potato clones was evaluated in a completely randomized design with three replicates. The experimental units were divided in two blocks (A) and (B). In (A), two leaf cuts were made, 75 and 150 days after planting. In (B), one leaf cut was made at the time of root harvest, 150 days after planting. A total of 27.5 statistically similar vegetative cuttings. Plants showed regular to good vigour-uniformity-cover and nil to medium flowering.

1. Centro de Investigación y Desarrollo Agrario del Perú. Investigador Asociado a la Universidad Alas Peruanas. e-mail: azquispe@hotmail. com 
Leaf yields in (A) oscillated between 41.36 to 933.09 t/ha and DLP-90052 was the best clon. In (B), yields oscillated between 16.97 and $49.44 \mathrm{t} /$ ha and DLP-2462 was the best clon. The average yield in (A) was $59.21 \mathrm{t} / \mathrm{ha}$ and $30.08 \mathrm{t} / \mathrm{ha}$ in (B). Root yield in (A) varied betwen 0 and $7.3 \mathrm{t} / \mathrm{ha}$ and in (B), root yield varied between 0 and $18.43 \mathrm{t} / \mathrm{ha}$. In both blocks, máximum yield was obtained with Toquecita. Eight clones did not produce roots. Average root yield in (A) was $0.94 \mathrm{t} /$ ha and $2.20 \mathrm{t} / \mathrm{ha}$ in (B). In both cases, highly significant differences were found. The highest leaf yield (+97\%) reduced root yield to $43 \%$. Commercial roots were equivalent to 65 to $76 \%$ of total root yield in (A) and (B), respectively.

Leaf dry matter yields varied between 3.33 to 9.39 t/ha and DLP-2462 was the best clon. Root dry matter yields varied between o and $4.36 \mathrm{t} / \mathrm{ha}$. Toquecita was the best clon. Leaf protein varied between 2.86 to $7.34 \mathrm{t} / \mathrm{ha}$. The best clones were Helena and DLP-2462 with 7.34 and $6.56 \mathrm{t} / \mathrm{ha}$, respectively. Root protein in Toquecita and Solapa (check) was 1.26 and $0.09 \mathrm{t} / \mathrm{ha}$, respectively.

An analysis of root/leaf relation showed that Toquecita can be considered for leaf and root production. All the other clones were only for leaf production. With new technology, Toquecita can produce 15 and 16 t/ha of leaf and roots, respectively. R:B/C 1.57 and S/. 4083/ha.

Key words: Ecosystems, dry forest, advanced selection, double purpose.

\section{INTRODUCCIÓN}

En el Perú, Piura es la región que destaca en la crianza de ganado caprino en el ecosistema de bosque seco, donde existe disponibilidad de pastos naturales entre enero a marzo y escasez de abril a diciembre y solo se cuenta con rastrojos secos principalmente de gramíneas anuales de baja palatabilidad y valor nutritivo (MINAG, Piura 2000).

La mayor parte de los bosques secos de la costa se ubica en el norte del país, entre los departamentos de Tumbes, Piura y Lambayeque, ocupando más de tres millones de hectáreas.

Esta frágil cobertura vegetal es vital para la crianza de caprinos y constituye el hábitat de unas 35,000 familias, en donde la mayor parte se encuentra en situación de pobreza y pobreza extrema (Cuba, 1998).

En años de ocurrencia del fenómeno El Niño (FEN) estas áreas producen un apreciable volumen de pastos naturales estimados entre 4 a $8 \mathrm{t} /$ ha, según ONGs y la Región Agraria Piura, y en los años sin FEN la producción es mínima. MINAG-Piura (2000).

La superficie de pastos cultivados es de solo 10,487 ha; las provincias con mayor área sembrada son Ayabaca, Huancabamba y Morropón. Las tres especies más importantes son el pasto elefante Pennicetum purpureum (ocupa el $40 \%$ de la superficie), el pasto castilla, Arundo donax y la paja chilena, Panicum máximun (PAEN/GTZ, 2002).

Sin embargo se aprecia que existe potencial para la producción de forrajes mejorados y la crianza de caprinos debido a las favorables condiciones agroecológicas del bosque seco donde se podría obtener buenos resultados y constituir una significativa fuente de trabajo e ingresos de las poblaciones más pobres y marginadas de la región.

El valle Quiroz-Piura es una típica zona representativa del piso ecológico bosque seco, donde el cultivo del camote, para producción de raíces, es ancestral y frecuente como fuente alimenticia, pero el cultivo de camote de doble propósito (para producción de forraje y raíces) es descono- 
cido, por lo que el inicio de ensayos para evaluar la adaptación y rendimiento de clones avanzados de camote mejorado es una excelente opción productiva la que permitirá en el futuro inmediato contar con nuevos materiales y fuentes de producción de forrajes y camote comestible al más bajo costo, disponibilidad inmediata y producción sostenida. En dicho contexto se plantearon los siguientes:

\section{Hipótesis:}

Hp = Los clones de selección avanzada de camote de doble propósito tienen igual adaptación y rendimiento de follaje y raíces reservantes en el bosque seco de Piura.

\section{Objetivos:}

1) Evaluar la adaptación y rendimiento de 20 clones de selección avanzada de camote de aptitud doble propósito -forraje y raíces- en los agroecosistemas de bosques secos de Piura.

2) Seleccionar el/los clon/es promisorio/s con alto potencial de rendimiento de forraje y raíces, que sean biológica y económicamente viables como cultivo de doble propósito.

3) Generar un nuevo paquete tecnológico apropiado con el/los clon/es promisorio/s.

\section{MÉTODOS Y MATERIALES}

\section{Ubicación del campo experimental:}

El ensayo se ha realizado en una parcela ubicada en el ecosistema de bosque seco, en el norte del Perú (frontera con el Ecuador), en el caserío Puente Quiroz-Piura, en $378 \mathrm{~m} 2$ de área neta. El Lugar Experimental tuvo las características que se presenta a continuación:

$\begin{array}{ll}\text { Parcela } & \text { : "Roberto". } \\ \text { Latitud } & : 04^{\circ} 30^{\prime} \mathrm{S} \\ \text { Longitud } & : 80^{\circ} 00^{\prime} \mathrm{O} \\ \text { Altitud } & : 430 \mathrm{msnm} \\ \text { Valle } & : \text { Quiroz } \\ \text { Distrito } & : \text { Suyo } \\ \text { Provincia/Región } & : \text { Ayabaca / Piura } \\ \text { Fecha de siembra } & : 21 \text { diciembre 2002 } \\ \text { Fecha de cosecha } & : 21 \text { mayo 2003 } \\ \text { Colaborador } & : \text { Vicente Moreno O. }\end{array}$

\section{Características físico - químicas del suelo}

Para el adecuado conocimiento de las características físico-químicas se realizó el análisis del suelo. Los resultados del Analisis del suelo ( $\mathrm{Ta}$ bla 1), indican textura franca, nitrógeno total y $\mathrm{K}$-asimilable bajo, $\mathrm{P}$-disponible medio y $\mathrm{pH}$ neutro, aceptables contenidos de nutrientes para el camote.

\section{Tabla $N^{\circ}$ 1. Características físico-químicas del suelo}

$\begin{array}{cccccc}\text { Descripción } & \text { Valor } & \text { Interpretación } & \text { Descripción } & \text { Valor } & \text { Interpretación } \\ \text { C.E. a } 25^{\circ} \mathrm{C} & 0.46 & \text { Muy baja } & \text { M. Orgánica } & 0.7 & \text { Bajo } \\ \mathrm{pH} & 6.88 & \text { Neutro } & \text { N. Total } & 0.04 & \text { Bajo } \\ \text { Calcáreo } & 0 & \text { Trazas } & \text { P-Disponible } & 13 & \text { Medio } \\ \mathrm{CIC} & 16.72 & \text { Medio } & \text { K-asimilable } & 170 & \text { Bajo } \\ \mathrm{Ca}++ & 12.8 & --- & \text { Arena } & 30 & \% \\ \mathrm{Mg}++ & 3.3 & --- & \text { Limo } & 47 & \% \\ \mathrm{~K}+ & 0.44 & --- & \text { Arcilla } & 23 & \% \\ \mathrm{Na}+ & 0.18 & --- & \text { Textura } & \text { Franco } & --\end{array}$




\section{Condiciones meteorológicas}

Las condiciones meteorológicas se presentan en la tabla No 2, muestra que la etapa experimental verano-otoño (diciembre 2002 y mayo 2003), fue un año seco normal (sin ocurrencia del FEN); las temperaturas promedio mínima, media y máxima fueron 21,$1 ; 26,2$ y $32,4^{\circ} \mathrm{C}$, con $5,5 \mathrm{hrs} /$ día promedio (170,9 horas de sol total); la humedad relativa fue de 69,0\%; y la precipitación total, solo 79,90 mm, apropiadas para el cultivo de camote.

Tabla No 2. Condiciones meteorológicas (diciembre 2002 - mayo 2003)

\begin{tabular}{ccccccc} 
Años/Meses & \multicolumn{3}{c}{ Temperaturas $\left({ }^{\circ} \mathrm{C}\right)$} & Horas de & $\mathrm{H}^{\circ}$. relativa. & $\begin{array}{c}\text { Precipitacion } \\
\text { Pluvial }\end{array}$ \\
& MINIMA & MEDIA & MAXIMA & SOL & $(\%)$ & $(\mathrm{mm})$ \\
DIC.2002 & 20,34 & 25,25 & 31,68 & 137,70 & 69,94 & 4,70 \\
ENE.2003 & 21,93 & 26,69 & 32,55 & 132,60 & 68,61 & 21,70 \\
FEB.2003 & 22,60 & 26,76 & 31,99 & 112,80 & 72,93 & 38,40 \\
MAR.2003 & 22,18 & 27,57 & 33,41 & 171,30 & 67,70 & 14,40 \\
ABR.2003 & 20,99 & 26,42 & 33,27 & 218,10 & 65,58 & 0,30 \\
MAY.2003 & 18,51 & 24,60 & 31,46 & 252,80 & 69,19 & 0,40 \\
Sumatoria & $\mathbf{1 2 6 , 5 5}$ & $\mathbf{1 5 7 , 2 9}$ & $\mathbf{1 9 4 , 3 6}$ & $\mathbf{1 0 2 5 , 3 0}$ & $\mathbf{4 1 3 , 9 5}$ & $\mathbf{7 9 , 9 0}$ \\
Promedios & $\mathbf{2 1 , 1}$ & $\mathbf{2 6 , 2}$ & $\mathbf{3 2 , 4}$ & $\mathbf{1 7 0 , 9}$ & $\mathbf{6 9 , 0}$ & $\mathbf{1 3 , 3}$ \\
& & & & & &
\end{tabular}

Tratamientos en estudio (Clones de selección avanzada).

En la Tabla 3, se presenta información sobre los tratamientos en estudio que fueron 20 clones de selección avanzada y Solapa (testigo).

Los tratamientos provienen del grupo de accesiones de aptitud forrajera y de doble propósito del Banco de Germoplasma de Camote del Centro Internacional de la Papa-CIP, los mismos que están calificados como clones de selección avanzada con potencial de rendimiento de forraje y raíces comestibles.

El clon Solapa (t), proviene de cultivos comerciales proporcionados por el agricultor-colaborador.

\section{Diseño experimental}

Se estableció el Diseño Bloques Completos al Azar con 3 repeticiones (DBCA/3r), distribuidos en $378 \mathrm{~m} 2$ de área neta. En cada unidad experimental (UE) de $6.0 \mathrm{~m} 2$ se sembraron 30 esquejes (3 surcos con 10 esquejes).

Las UE fueron divididas en dos franjas: A y B de 3,0 m2 cada franja. En la Franja A, se hizo dos cortes de follaje, A1 (Inicial) y A2 (Rebrote) a los 75 y 150 dds; son los cortes mejorados, y en la franja B, un corte (Único) a los 150 dds, corte tradicional, realizado junto con la cosecha de raíces reservantes. En los gráficos $1 \mathrm{~A}$ y $1 \mathrm{~B}$ se detalla el DBCA/3r, y el Cuadro 4 muestra detalles de la UE. 
Tabla N 3 . Tratamientos en estudio (Clones de selección avanzada).

$\begin{array}{cccccc}\text { Tratamientos } & \begin{array}{c}\text { Número } \\ \text { CIP }\end{array} & \begin{array}{c}\text { Número de } \\ \text { Colección }\end{array} & \begin{array}{c}\text { Nombre } \\ \text { Clones }\end{array} & \begin{array}{c}\text { País de } \\ \text { Origen }\end{array} & \begin{array}{c}\text { Código del } \\ \text { Donante }\end{array} \\ \text { T-1 } & 401466 & \text { CC-89.213 } & \text { CC89.213 } & --- & \text { CIP-COOP-N/A } \\ \text { T-2 } & 421383 & \text { DLP-3548 } & \text { DLP-3548 } & \text { PER } & --- \\ \text { T-3 } & 420250 & \text { DLP-2462 } & \text { DLP-2462 } & \text { PER } & \text { CIP-COOP-N/A } \\ \text { T-4 } & 420855 & \text { DLP-2481 } & \text { DLP-2481 } & \text { PER } & \text { CIP-COOP-N/A } \\ \text { T-5 } & --- & \text { DLP-90025 } & \text { DLP-90025 } & --- & --- \\ \text { T-6 } & 190023.59 & \text { SR-90.323 } & \text { SR 90.323 } & --- & --- \\ \text { T-7 } & 420068 & \text { ARBUNAP-55 } & \text { Helena } & \text { PER } & \text { CIP-PER-UNAP } \\ \text { T-8 } & 420120 & \text { ARB-394 } & \text { Pikis } & \text { PER } & \text { CIP-PER- } \\ \text { T-9 } & 420152 & \text { ARBUNAP-74 } & \text { Kumala } & \text { PER } & \text { CIP-PER-UNAP } \\ \text { T-10 } & 420248 & \text { DLP-2448 } & \text { Dulce } & \text { PER } & \text { CIP-COOP-N/A } \\ \text { T-11 } & 420386 & \text { ARB-158 } & \text { Acaro } & \text { PER } & \text { CIP-PER- } \\ \text { T-12 } & 420439 & \text { ARB-265 } & \text { Calabacito } & \text { PER } & \text { CIP-PER- } \\ \text { T-13 } & 420476 & \text { ARB-389 } & \text { Yema Huevo } & \text { PER } & \text { CIP-PER- } \\ \text { T-14 } & 420713 & \text { DLP-1308 } & \text { Morado } & \text { PER } & \text { CIP-COOP-N/A } \\ \text { T-15 } & 420967 & \text { DLP-3525 } & \text { Unknown } & \text { PER } & \text { CIP-COOP-N/A } \\ \text { T-16 } & 421083 & \text { RCB-IN-5 } & \text { Tipo 3 } & \text { PER } & \text { CIP-PER-RCB } \\ \text { T-17 } & 440034 & \text { BDI-Mohc } & \text { Mohc } & \text { BDI } & \text { CIP-BDI-ISABU } \\ \text { T-18 } & 440045 & \text { SPV-55 } & \text { Toquecita } & \text { PRI } & \text { CIP-USA-USDA } \\ \text { T-19 } & 440049 & \text { SPV-65 } & \text { Mojave } & \text { PRI } & \text { CIP-USA-USDA } \\ \text { T-20 } & 420169 & \text { DLP-275a } & \text { Tabón } & \text { PER } & \text { CIP-COOP-N/A } \\ \text { T-21 } & -\cdots & --- & \text { Solapa (t) }(1) & \text { PER } & --- \\ & & & & & \end{array}$

Tabla $N^{\circ} 4$. Detalle de la unidad experimental

$\begin{array}{cccc}\begin{array}{c}\text { Distancia entre } \\ \text { surcos }\end{array} & 1,0 \mathrm{~m} & \text { \# U.E. } & 63 \\ \begin{array}{c}\text { Distancia entre } \\ \text { plantas }\end{array} & 0,2 \mathrm{~m} & \text { Surcos/U.E. } & 3 \\ \text { Largo U.E. } & 3 \mathrm{~m} & \text { Esquejes/surco } & 10 \\ \text { Ancho U.E. } & 2 \mathrm{~m} & \text { Esquejes/U.E. } & 30 \\ \text { Area U.E. } & 6,0 \mathrm{~m} 2 & \text { Área Neta } & 378 \mathrm{~m} 2 \\ \text { Area/franja } & 3,0 \mathrm{~m} 2 & \text { Área Calles } & 274 \mathrm{~m} 2 \\ \text { Área/planta } & 0,20 \mathrm{~m} 2 & \text { Área Total } & 652 \mathrm{~m} 2 \\ & & & \end{array}$



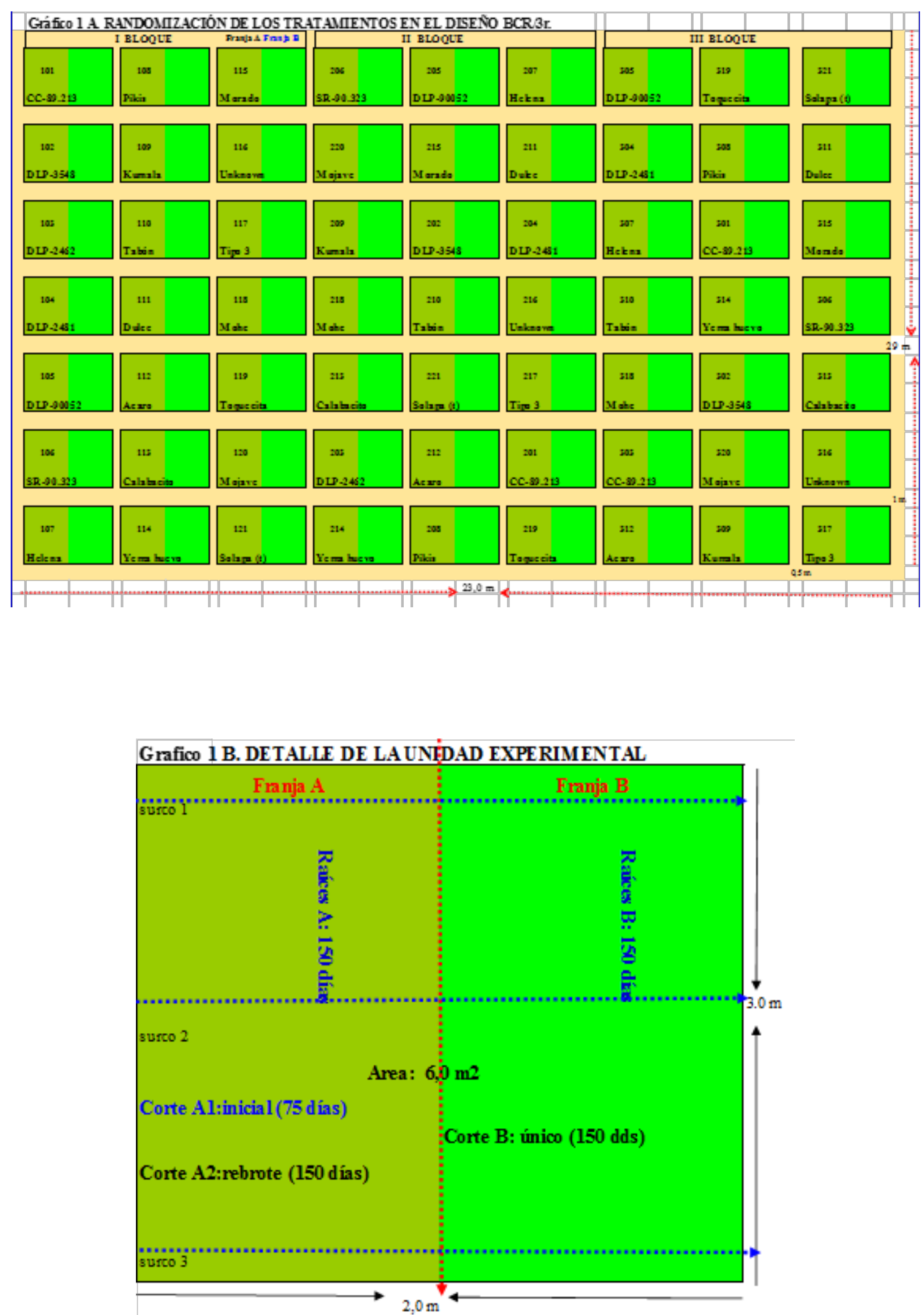

RENDIMIENTOS:

Follaje $\mathrm{A}=$ Corte $\mathrm{A} 1+$ Corte $\mathrm{A} 2$

Raices $\mathrm{A}=$ Cosecha $\mathrm{A}$

Follaje $\mathrm{B}=$ Corte $\mathrm{B}$.

Raices $B=$ Cosech $B$. 


\section{Modelo Aditivo Lineal:}

$Y i j=\mu+\beta i+\tau j+€ i j$

Yij = Valor observado por el efecto del i-ésimo bloque, j-ésimo tratamiento

$\mu$ = Efecto de la media general;

$\beta \mathrm{i}=$ Efecto del i_ésimo bloque;

$\tau j=$ Efecto del j_ésimo tratamiento;

Gij $=$ Efecto del error experimental.

Análisis estadísticos:

Los Análisis Estadísticos de las Evaluaciones Experimentales planeadas se registraron cronológicamente en el cuaderno de campo (Tabla 5).
Para establecer las diferencias estadísticas de los parámetros evaluados entre los tratamientos se realizó los respectivos Análisis de Variancia (ANVA) y las Pruebas de DUNCAN para las comparaciones de medias, lo que se refuerza la confiabilidad y consistencia de los resultados.

Al respecto, Calzada (1995) indica que los resultados observados, aparte de su cuidadoso registro en campo, se deben someter al rigor de los Análisis Estadísticos; para el procesamiento de la data experimental se planea utilizar la versión 9.1 del programa estadístico SAS.

\section{Tabla $N^{\circ}$ 5. Evaluaciones Experimentales}

\begin{tabular}{|c|c|c|}
\hline Ord & $\begin{array}{l}\text { Parámetros en } \\
\text { Evaluación }\end{array}$ & dds \\
\hline 1 & $\begin{array}{l}\text { Siembra del } \\
\text { Experimento }\end{array}$ & 0 \\
\hline 2 & $\begin{array}{l}\text { Evaluación de } \\
\text { prendimiento }\end{array}$ & 21 \\
\hline 3 & $\begin{array}{l}\text { Evaluación de } \\
\text { VUC }\end{array}$ & 50 \\
\hline 4 & $\begin{array}{l}\text { Evaluación de } \\
\text { floración }\end{array}$ & 90 \\
\hline 5 & $\begin{array}{c}\text { Corte Inicial } \\
\text { (A1) y pesado } \\
\text { follaje } \\
\text { Corte Rebrote }\end{array}$ & 75 \\
\hline 6 & $\begin{array}{l}\text { (A2) y pesado } \\
\text { follaje }\end{array}$ & 150 \\
\hline 7 & $\begin{array}{l}\text { Corte Único (B) } \\
\text { y pesado follaje }\end{array}$ & 150 \\
\hline 8 & $\begin{array}{c}\text { Cosecha } \\
\text { Raíces } \\
\text { Reservantes en } \\
\text { A } \\
\text { Cosecha }\end{array}$ & 150 \\
\hline 9 & $\begin{array}{c}\text { Raíces } \\
\text { Reservantes en } \\
\text { B. } \\
\text { Evaluaciones y }\end{array}$ & 150 \\
\hline 10 & $\begin{array}{l}\text { Análisis en } \\
\text { Gabinete }\end{array}$ & $>150$ \\
\hline
\end{tabular}




\section{Metodología experimental}

El ensayo se desarrolló con la metodología Escuelas de campo para agricultores (ECA's), modelado por CIP-CARE (2002).

Ésta provee a los agricultores-colaboradores la oportunidad de aprender-e-investigar sobre principios que son conocidos por la ciencia formal, con un enfoque de Investigación Participativa en parcela de agricultor.

Durante el proceso experimental se tomó los lineamientos pertinentes de la Resolución Jefatural N 020-2000. INIA-AG; que considera las Normas para el Liberación de nuevo cultivar.

A fin de hacer los ajustes de las Escalas de Evaluación y disponer de esquejes-semilla en forma oportuna, se realizó una campaña agrícola previa al ensayo.

Se espera que el proceso experimental, permita generar un nuevo paquete tecnológico adaptado a las condiciones del ecosistema de bosque en la que no se considera la aplicación de agroquímicos.

\section{Manejo agronómico del ensayo}

El ensayo se ha conducido en base a las típicas labores culturales de un cultivo de camote local (tecnología tradicional) a la que se ha imputado algunos ajustes y/o modificaciones (tecnología mejorada) como son:

1. Siembra en surcos, y plantación de un solo esqueje/hoyo.

2. NPK 190-80-60 kg/ha, con estiércol de cabra, (basada en los análisis de suelo).

3. Cinco riegos oportunos, y tres deshierbos a los 20,75 y 120 dds.

4. Instalación de 50 trampas amarillas.
5. Aplicación de biocidas (20 y 6 Lt/ha de "biol” y caldo sulfocálcico).

6. Corte de follaje inicial y rebrote en franja (A).

\section{Escalas de evaluación}

Las Escalas de Evaluación (Tabla 6), facilitados por Molina (2002) tuvieron los valores: 1, 3, 5, 7 y 9 , donde 1 y $9=$ mínimo y máximo valor, 5 se considera valor normal, las que se ajustaron in situ en campaña agrícola previa en forma conjunta con el investigador.

\section{Parámetros de evaluación}

Los Parámetros de Evaluación establecidos se ordenaron en:

1. Parámetros de crecimiento (PCr).

2. Parámetros de productividad (PPd).

3. Parámetros de calidad (PCd).

Parámetros de crecimiento (PCr)

Prendimiento de esquejes (\#).

En cada UE se planeó sembrar 30 esquejes (25-30 $\mathrm{cm}$ de longitud).

El conteo del prendimiento de los esquejes se realiza a los 7, 14 y 21 días después de la siembra (dds); a los 21 dds se espera que los esquejes ya estén establecidos. 


\section{RESULTADOS}

Parámetros de crecimiento (PCr):

Prendimiento de Esquejes (\#).

Los resultados muestran (Tabla 6) que se obtuvo 27.5 esquejes prendidos en promedio $(91,53 \%)$ para todo el ensayo sin diferencias estadísticas (ANVA 1, DUNCAN 1). Estos valores revelan un buen estado inicial de plantas.

Tabla $N^{\circ}$ 6. Parámetros de crecimiento (PCr).

\begin{tabular}{|c|c|c|c|c|c|}
\hline $\begin{array}{c}\text { Clones } \\
\text { (Tratamientos } \\
\text { ) }\end{array}$ & $\begin{array}{l}\text { Prendimiento } \\
\text { (\#) ns / Duncan }\end{array}$ & Vigor & Uniformidad & Cobertura & Floración \\
\hline Acaro & $28^{a}$ & 8 & 6 & 6 & 2 \\
\hline Mojave & $29^{a}$ & 6 & 7 & 6 & 1 \\
\hline Helena & $30^{a}$ & 6 & 5 & 8 & 2 \\
\hline SR-90.323 & $29^{a}$ & 8 & 4 & 7 & 2 \\
\hline Toquecita & $29^{a}$ & 6 & 7 & 6 & 7 \\
\hline Kumala & $29^{a}$ & 6 & 6 & 6 & 1 \\
\hline Unknown & $27^{a}$ & 6 & 6 & 6 & 3 \\
\hline DLP-2462 & $27^{a}$ & 4 & 7 & 6 & 2 \\
\hline Mohc & $27^{a}$ & 5 & 6 & 6 & 7 \\
\hline Solapa (t) & $26^{a}$ & 5 & 6 & 6 & 4 \\
\hline Dulce & $27^{a}$ & 4 & 6 & 6 & 2 \\
\hline DLP-3548 & $26^{a}$ & 5 & 6 & 6 & 2 \\
\hline Morado & $27^{a}$ & 6 & 5 & 6 & 1 \\
\hline DLP-2481 & $29^{a}$ & 6 & 5 & 5 & 1 \\
\hline Tipo 3 & $26^{a}$ & 5 & 5 & 5 & 4 \\
\hline DLP-90052 & $27^{\mathrm{a}}$ & 4 & 6 & 5 & 5 \\
\hline CC-89.213 & $28^{a}$ & 5 & 4 & 5 & 2 \\
\hline Calabacito & $25^{a}$ & 6 & 3 & 5 & 1 \\
\hline Pikis & $29^{a}$ & 5 & 5 & 4 & 1 \\
\hline Tabón & $26^{a}$ & 6 & 4 & 4 & 5 \\
\hline $\begin{array}{c}\text { Yema de } \\
\text { huevo }\end{array}$ & $27^{\mathrm{a}}$ & 6 & 3 & 4 & 1 \\
\hline Promedios & 27,5 & 5,5 & 5,4 & 5,6 & 3 \\
\hline Coef. Var. (\%) & 8,06 & --- & --- & --- & --- \\
\hline
\end{tabular}

Los cinco clones más destacados son Helena, Toquecita, Mojave, SR-90.323 y Kumala con 30, 29, 29,29, y 29 esquejes prendidos.
Solapa (t) logró 26 esquejes prendidos. El valor promedio de $91.53 \%$ logrado es aceptable y es ligeramente menor a $96.13 \%$ y $98.75 \%$ obtenidos en La Molina por Salas (2002) y en Cañete por Rabines (1993). 


\section{Vigor-Uniformidad-Cobertura de plantas (VUC)}

Los resultados promedio de VUC son 5,5 - 5,4 - 5,6 para todos los tratamientos (Tabla 7), estos valores indican que las plantas mostraron Regular a Buen VUC destacan Acaro, Mojave, Helena, SR-90.323 y Toquecita; Solapa (t) logra 5-6-6.

Estos valores son congruentes a los valores de Regular a Bueno, obtenidos por Julca (2014), y Regular a Buen Vigor, obtenido por Rabines (1993). A priori, estos resultados más el prendimiento muestran la inicial buena performance de los clones en evaluación.

\section{Floración de plantas}

Los valores obtenidos fueron ocho, nueve y dos, lo que indica que los clones tuvieron nula, pobre, regular floración y solo los clones Toquecita y Mohc profusa floración (Tabla 7).

Al respecto existe limitada información bibliográfica sobre la evaluación de floración en este tipo de ensayos, pudiéndose tomar como un caso-tipo.

La importancia de los valores obtenidos es relativa en investigaciones agronómicas, siendo su importancia mayor en investigaciones de mejoramiento genético.

\section{Parámetros de productividad (PPd):}

Rendimiento de follaje fresco (t/ha).

En la franja (A), los rendimientos de follaje del corte A1 fluctúan de 52,19 a 24,16 y promedio de $38,32 \mathrm{t} / \mathrm{ha}$, con diferencias significativas entre los clones (tratamientos) ANVA 2 (Tabla 8).

DUNCAN 2 muestra que destaca DLP-90052, y supera con 52.19 t/ha, a Morado, Mojave, SR90.323 y DLP-2481, con 50,57; 47,24; 44,13 y 44,11 t/ha. Solapa (t), con 37,92 t/ha, ocupa la 6ta posición.

los rendimientos de corte A1 (inicial) equivalen al $65 \%$ del rendimiento total de follaje.

Los rendimientos del corte A2 (rebrote) fluctúan de 40,90 a 17,20 y promedio de 20,89 t/ha, existiendo diferencias altamente significativas entre clones.

El ANVA 3 y DUNCAN 3, muestra que DLP90052 produce 40,90 t/ha y supera a Mojave, DLP-2462, Mohc y Solapa (t), los cuales producen 36,$59 ; 29,84 ; 25,43$ y $25,33 \mathrm{t} /$ ha, siendo los cinco clones más productivos y estadísticamente superiores a los 16 clones restantes. Los rendimientos del corte A2, son menores al de A1 y equivale al 35\% del rendimiento total de follaje.

\section{Tabla $N^{\circ}$ 7. Rendimiento de follaje fresco (t/ha).}

\begin{tabular}{|c|c|c|c|c|c|c|c|c|c|}
\hline \multirow{3}{*}{$\begin{array}{l}\text { Clones } \\
\text { (Tratamientos) }\end{array}$} & \multicolumn{5}{|c|}{ Franja A } & \multicolumn{2}{|c|}{ Total A1+A2 } & \multicolumn{2}{|c|}{ Franja B } \\
\hline & \multicolumn{2}{|c|}{ Corte A1 } & \multirow{2}{*}{ DUNCAN 2} & Corte A2 & \multirow{2}{*}{ DUNCAN 3} & \multirow{2}{*}{ ANVA 4 ** } & \multirow{2}{*}{ DUNCAN 4} & \multirow{2}{*}{$\underset{* *}{\text { Corte B ANVA } 5}$} & \multirow{2}{*}{ DUNCAN 5} \\
\hline & ANVA 2 & * & & ANVA 3 ** & & & & & \\
\hline DLP-90052 & 52,19 & & a & 40,90 & a & 93,09 & a & 27,47 & efgh \\
\hline Mojave & 47,24 & & $a b c$ & 36,59 & a & 83,83 & $a b$ & 46,79 & $a b$ \\
\hline Morado & 50,57 & & $a b$ & 21,15 & cde & 71,72 & $\mathrm{bc}$ & 41,19 & $a b c$ \\
\hline DLP-2462 & 38,61 & & abcde & 29,84 & b & 68,45 & $\mathrm{bc}$ & 49,44 & a \\
\hline SR-90.323 & 44,13 & & abcd & 19,40 & cde & 63,53 & bcd & 33,26 & cde \\
\hline Solapa (t) & 37,92 & & abcde & 25,33 & $\mathrm{bc}$ & 63,25 & bcd & 31,11 & defg \\
\hline DLP-3548 & 40,07 & & abcde & 20,66 & cde & 60,73 & $c d$ & 27,40 & efgh \\
\hline Calabacito & 39,21 & & abcde & 20,60 & cde & 59,81 & $c d$ & 32,91 & cde \\
\hline Acaro & 39,82 & & abcde & 19,56 & cde & 59,38 & $c d$ & 37,41 & cd \\
\hline Dulce & 43,57 & & abcd & 14,72 & e & 58,29 & cd & 19,03 & hi \\
\hline DLP-2481 & 44,11 & & abcd & 13,81 & e & 57,92 & $c d$ & 21,92 & ghi \\
\hline Kumala & 33,06 & & bcde & 24,66 & bcd & 57,72 & cd & 31,09 & defg \\
\hline
\end{tabular}




\begin{tabular}{|c|c|c|c|c|c|c|c|c|}
\hline Unknown & 42,28 & abcde & 15,36 & e & 57,64 & cd & 31,69 & def \\
\hline Mohc & 31,21 & cde & 25,43 & $\mathrm{bc}$ & 56,64 & cd & 32,69 & cde \\
\hline Tipo 3 & 41,36 & abcde & 13,50 & e & 54,86 & cd & 23,98 & efghi \\
\hline Tabón & 34,21 & abcde & 18,65 & cde & 52,86 & cd & 16,97 & $\mathrm{i}$ \\
\hline Yema huevo & 35,73 & abcde & 15,00 & e & 50,73 & cd & 20,34 & hi \\
\hline Helena & 30,71 & cde & 16,63 & e & 47,34 & cd & 40,18 & bcd \\
\hline CC-89.213 & 28,56 & cde & 14,11 & e & 42,67 & d & 23,05 & fghi \\
\hline Toquecita & 25,92 & de & 15,58 & e & 41,50 & d & 19,59 & hi \\
\hline Pikis & 24,16 & e & 17,20 & de & 41,36 & $d$ & 24,24 & efghi \\
\hline Promedios & 38,32 & --- & 20,89 & --- & 59,21 & --- & 30,08 & -- \\
\hline Porcentajes & $65 \%$ & --- & $35 \%$ & --- & $100 \%$ & --- & $100 \%$ & --- \\
\hline
\end{tabular}

El rendimiento total en franja (A) (cortes A1 + A2) fluctúan de 93,09 a 41,36 y promedio de 59,21 t/ha, (Tabla 7) con diferencias altamente significativas entre bloques y entre tratamientos.

El ANVA 4 y DUNCAN 4 indican que DLP90052 supera con 93,09 t/ha a Mojave, Morado, DLP-2462 y SR-90.323, con 83,03; 71,72; 68,45 y $63,53 \mathrm{t} / \mathrm{ha}$, siendo estadísticamente superiores, y son los cinco clones más productivos frente a los 16 clones restantes. Solapa (t), con 63,25 t/ha, ocupa el 6to lugar. Los rendimientos totales obtenidos en (A) son menores a 111,63-87,18 t/ha, logrados en Argentina por Martí, H. (2003).

En la franja (B), los rendimientos del corte único fluctúan de 49,44 a 16,97 y promedio $30,08 \mathrm{t} / \mathrm{ha}$, existiendo diferencias altamente significativas para bloques y entre tratamientos ANVA 5 (Cuadro 8). Según DUNCAN 5 destaca DLP-2462 con 49,44 t/ha y es estadísticamente superior a Mojave, Morado, Helena y Acaro con 46,79; 41,19; 40,18 y $37,41 \mathrm{t} /$ ha respectivamente.

Solapa (t), produce 31,11 t/ha. Se observa que 16 clones producen rendimientos inferiores a 33,26 $\mathrm{t} / \mathrm{ha}$ e iguales a $16,97 \mathrm{t} / \mathrm{ha}$, demostrando que son clones menos productivos.

Agronómicamente estos 16 clones requieren cortes oportunos cada 75 días para ser más productivos y así evitar la pérdida del follaje pronta senescencia.

\section{Rendimientos Totales Comparativos de Follaje ( $t$ / ha) en franja (A) y (B)}

Los rendimientos totales comparativos de follaje fresco en las franjas (A) y (B), (Tabla 8), muestran que el rendimiento promedio en la franja (B) (corte B) es de 30,08 t/ha (100\%) que es menor al rendimiento en (A) de 59,21 t/ha, lo cual equivale a $197 \%$ respecto a B. Destaca en A el clon DLP-90025 como el máximo productor de follaje (Tabla 9).

Globalmente se puede concluir que el rendimiento promedio de follaje con dos cortes (A1 y A2) en la franja A fue de 59,21 t/ha (197\%), y en la franja $\mathrm{B}$, de 30,08 t/ha (100\%) con corte único, destacando DLP-2462 con 49,44 t/ha.

\section{Rendimiento de raíces reservantes en (A) y (B) (t/} ha)

Están referidos a los rendimientos de raíces reservantes comerciales (RR-C) y raíces reservantes no comerciales (RR-nC) en las franjas (A) y (B).

\section{En la franja (A)}

Los rendimientos de raíces reservantes comerciales [RR-C(A)] fluctúan de 5,80 a 0,00 y promedio de 0,61 t/ha, con diferencias altamente significativas entre los clones. ANVA 6 y DUNCAN 6 muestran que destaca el clon Toquecita 
con 5,80 t/ha que ocupa el ler lugar, superando estadísticamente a todos los clones (Tabla 9), y se observa que 15 clones y Solapa $(\mathrm{t})$ no producen raíces comerciales $(0,00 \mathrm{t} / \mathrm{ha})$ y son estadísticamente iguales.

El rendimiento de raíces comerciales en franja (A) equivale al $65 \%$ del rendimiento total.
Se puede afirmar que los cortes A1 y A2 (mejorados) reducen o limitan significativamente la producción de raíces reservantes, las que podrían atribuirse al corto periodo vegetativo del follaje (75 días).

Estas raíces tienen buenos precios en el mercado fronterizo "Feria Libre de los martes" en las localidades de La Tina (Perú) y Macará (Ecuador).

Tabla No 8 . Rendimientos Totales Comparativos de Follaje (t/ha)

\begin{tabular}{ccc}
$\begin{array}{c}\text { Clones } \\
\text { (Tratamiento } \\
\text { s) }\end{array}$ & $\begin{array}{c}\text { TOTAL (A) } \\
\text { (A1+A2) }\end{array}$ & TOTAL (B) \\
DLP-90052 & 93,09 & 27,47 \\
Tabón & 52,86 & 16,97 \\
Dulce & 58,29 & 19,03 \\
DLP-2481 & 57,92 & 21,92 \\
Yema huevo & 50,73 & 20,34 \\
Tipo 3 & 54,86 & 23,98 \\
DLP-3548 & 60,73 & 27,40 \\
Toquecita & 41,50 & 19,59 \\
Solapa (t) & 63,25 & 31,11 \\
SR-90.323 & 63,53 & 33,26 \\
Kumala & 57,72 & 31,09 \\
CC-89.213 & 42,67 & 23,05 \\
Unknown & 57,64 & 31,69 \\
Calabacito & 59,81 & 32,91 \\
Mojave & 83,83 & 46,79 \\
Morado & 71,72 & 41,19 \\
Mohc & 56,64 & 32,69 \\
Pikis & 41,36 & 24,24 \\
Acaro & 59,38 & 37,41 \\
DLP-2462 & 68,45 & 49,44 \\
Helena & 47,34 & 40,18 \\
Promedios & $\mathbf{5 9 , 2 1}$ & $\mathbf{3 0 , 0 8}$ \\
Porcentajes & $\mathbf{1 9 7 \%}$ & $\mathbf{1 0 0 \%}$ \\
& & \\
\hline
\end{tabular}

Los rendimientos de raíces reservantes no comerciales [RR-nC(A)] fluctúan de 1,50 a 0,00 y promedio de $0,33 \mathrm{t} / \mathrm{ha}$, con diferencias altamente significativas entre clones (Tabla 9).

El ANVA 7 y DUNCAN 7 muestran que Toquecita ocupa el ler lugar con 1,50 t/ha, y supera es- tadísticamente a todos los tratamientos. Solapa $(\mathrm{t})$, produce $0,48 \mathrm{t} / \mathrm{ha}$. Así mismo se observa que ocho (8) clones no producen raíces no comerciales $(0,00 \mathrm{t} / \mathrm{ha})$.

El rendimiento de raíces no comerciales en (A) equivale al 35\% del rendimiento total. Este tipo 
de raíces en el valle Quiroz, tiene amplia aceptación para la alimentación de cerdos.

Los rendimientos de raíces reservantes totales [RR-Tot(A)] -comerciales y no comerciales- fluctúan de 7,30 a 0,00 y promedio 0,94 t/ha. Según el ANVA 8 existen diferencias significativas para bloques y altamente significativas entre clones.
DUNCAN 8 muestra que Toquecita ocupa el ler lugar con 7,30 t/ha, superando a todos los clones.

Solapa ( $\mathrm{t}$ ) produce $0,48 \mathrm{t} / \mathrm{ha}$; Se observa que ocho clones producen raíces entre 0,74 y $0,24 \mathrm{t} / \mathrm{ha}, \mathrm{y}$ otros ocho clones no producen raíces reservantes $(0,00 \mathrm{t} / \mathrm{ha})$, y se considera que son clones que tienen o son de aptitud forrajera.

Tabla Nº. Rendimientos de Raíces Reservantes en franja (A) (t/ha).

\begin{tabular}{|c|c|c|c|c|c|c|}
\hline \multirow{3}{*}{$\begin{array}{c}\text { Clones } \\
\text { (Tratamiento } \\
\text { s) }\end{array}$} & \multicolumn{6}{|c|}{ Franja (A) } \\
\hline & RR-C(A) & DUN- & RR-nC(A) & DUN CAMI & RR-Tot(A) & DUN- \\
\hline & ANVA $6^{* *}$ & CAN 6 & ANVA $7{ }^{* *}$ & DUIV-CAIV & ANVA 8** & CAN 8 \\
\hline Toquecita & 5,80 & a & 1,50 & a & 7,30 & a \\
\hline Mohc & 3,50 & $\mathrm{~b}$ & 0,53 & c & 4,03 & $\mathrm{~b}$ \\
\hline Tabón & 1,25 & d & 0,71 & b & 1,96 & c \\
\hline SR-90.323 & 1,60 & c & 0,53 & c & 2,13 & c \\
\hline CC-89.213 & 0,65 & e & 0,35 & cde & 1,00 & d \\
\hline Kumala & 0,00 & $\mathrm{f}$ & 0,50 & $\mathrm{~cd}$ & 0,50 & ef \\
\hline DLP-2481 & 0,00 & $f$ & 0,74 & b & 0,74 & de \\
\hline Solapa (t) & 0,00 & f & 0,48 & cd & 0,48 & ef \\
\hline Tipo 3 & 0,00 & $f$ & 0,33 & de & 0,33 & $\mathrm{fg}$ \\
\hline Pikis & 0,00 & $f$ & 0,35 & cde & 0,35 & $\mathrm{fg}$ \\
\hline Yema huevo & 0,00 & $f$ & 0,50 & cd & 0,50 & ef \\
\hline Unknown & 0,00 & f & 0,24 & e & 0,24 & $\mathrm{fg}$ \\
\hline DLP-2462 & 0,00 & f & 0,27 & e & 0,27 & $\mathrm{fg}$ \\
\hline DLP-3548 & 0,00 & f & 0,00 & $f$ & 0,00 & g \\
\hline DLP-90052 & 0,00 & f & 0,00 & $f$ & 0,00 & g \\
\hline Helena & 0,00 & f & 0,00 & f & 0,00 & g \\
\hline Dulce & 0,00 & f & 0,00 & f & 0,00 & g \\
\hline Acaro & 0,00 & $f$ & 0,00 & $f$ & 0,00 & g \\
\hline Calabacito & 0,00 & f & 0,00 & f & 0,00 & g \\
\hline Morado & 0,00 & $f$ & 0,00 & $f$ & 0,00 & g \\
\hline Mojave & 0,00 & $f$ & 0,00 & $f$ & 0,00 & g \\
\hline Promedios & 0,61 & --- & 0,33 & --- & 0,94 & --- \\
\hline C.V. (\%) & 27,86 & --- & 30,14 & --- & 22,15 & --- \\
\hline Porcentaje & $65 \%$ & --- & $35 \%$ & --- & $100 \%$ & --- \\
\hline
\end{tabular}

\section{En la franja (B)}

Los rendimientos de raíces reservantes comerciales [RR-C (B)] fluctúan de 16,35 a 0,00 y promedio de 1,67 t/ha con diferencias altamente significativas ANVA 9. DUNCAN 9 muestra que Toquecita ocupa el ler lugar con 16,35 t/ha, su- perando a Mohc, SR-90.323, Tabón y CC-89.213, las que producen 7,$00 ; 4,00 ; 3,42$ y $2,23 \mathrm{t} / \mathrm{ha}, \mathrm{y}$ son los cinco clones más productivos formando el 1er grupo de mayor rendimiento; luego se observa un 2do grupo integrado por Kumala, Solapa (t) y Tipo-3, con 1,00; 0,90 y 0,16 t/ha, y finalmente se observa el 3er grupo de 13 clones 
que no producen raíces comerciales $(0,00 \mathrm{t} / \mathrm{ha})$, siendo estadísticamente iguales (Cuadro 10).

El rendimiento total de raíces comerciales en la franja (B) se incrementa a 76\% (11\% más que en franja $A)$.

Esto se debe a que las plantas en la franja (B) con mayor periodo vegetativo producen más raíces reservantes de formas típicas y mayor valor comercial.

Los rendimientos de raíces reservantes no comerciales [RR-nC (B)] fluctúan de 2,08 a 0,00 y promedio de $0,53 \mathrm{t} /$ ha (Tabla 9 ); con alta diferen- cia estadística ANVA 10. DUNCAN 10 muestra que Toquecita ocupa el 1er lugar con 2,08 t/ha, superando a todos los clones; Solapa $(\mathrm{t})$ produce $0,49 \mathrm{t} / \mathrm{ha}$.

En este grupo, ocho clones no producen raíces reservantes, siendo estadísticamente iguales. El rendimiento de raíces no comerciales en la franja (B) se reduce a $24 \%$ del rendimiento total [en (A) es $35 \%$ ].

Este $24 \%$ es importante porque el objetivo en el proceso es producir más raíces comerciales y menos raíces no comerciales.

Tabla N ${ }^{\circ}$ 10. Rendimientos Totales de Raíces Reservantes Franja (B) (t/ha).

\begin{tabular}{|c|c|c|c|c|c|c|}
\hline \multirow{3}{*}{$\begin{array}{c}\text { Clones } \\
\text { (Tratamiento } \\
\text { s) }\end{array}$} & \multicolumn{6}{|c|}{ Franja (B) } \\
\hline & RR-C(B) & & RR-nC(B) & & RR-Tot(B) & \\
\hline & ANVA $9{ }^{* *}$ & DUNCAN 9 & ANVA $10^{* *}$ & DUNCAN 10 & ANVA $11^{* *}$ & DUNCAN 11 \\
\hline Toquecita & 16,35 & a & 2,08 & a & 18,43 & a \\
\hline Mohc & 7,00 & $\mathrm{~b}$ & 0,66 & de & 7,66 & b \\
\hline Tabón & 3,42 & c & 1,19 & c & 4,61 & c \\
\hline SR-90.323 & 4,00 & c & 0,33 & gh & 4,33 & c \\
\hline CC-89.213 & 2,23 & d & 0,25 & hi & 2,48 & $d$ \\
\hline Kumala & 1,00 & e & 1,32 & c & 2,32 & de \\
\hline DLP-2481 & 0,00 & $f$ & 1,60 & $\mathrm{~b}$ & 1,60 & ef \\
\hline Solapa (t) & 0,90 & e & 0,49 & efgh & 1,39 & $\mathrm{fg}$ \\
\hline Tipo 3 & 0,17 & $f$ & 0,72 & de & 0,89 & fgh \\
\hline Pikis & 0,00 & $f$ & 0,85 & d & 0,85 & fgh \\
\hline Yema huevo & 0,00 & $f$ & 0,63 & def & 0,63 & gh \\
\hline Unknown & 0,00 & $f$ & 0,57 & defg & 0,57 & gh \\
\hline DLP-2462 & 0,00 & $f$ & 0,35 & fgh & 0,35 & h \\
\hline DLP-3548 & 0,00 & $f$ & 0,00 & $\mathrm{i}$ & 0,00 & $\mathrm{~h}$ \\
\hline DLP-90052 & 0,00 & $f$ & 0,00 & $\mathrm{i}$ & 0,00 & h \\
\hline Helena & 0,00 & $f$ & 0,00 & $\mathrm{i}$ & 0,00 & h \\
\hline Dulce & 0,00 & $f$ & 0,00 & $\mathrm{i}$ & 0,00 & h \\
\hline Acaro & 0,00 & $f$ & 0,00 & $\mathrm{i}$ & 0,00 & h \\
\hline Calabacito & 0,00 & $f$ & 0,00 & $\mathrm{i}$ & 0,00 & h \\
\hline Morado & 0,00 & $f$ & 0,00 & $\mathrm{i}$ & 0,00 & h \\
\hline Mojave & 0,00 & $f$ & 0,00 & $\mathrm{i}$ & 0,00 & $\mathrm{~h}$ \\
\hline Promedios & 1,67 & --- & 0,53 & --- & 2,20 & --- \\
\hline C.V. (\%) & 22,87 & --- & 29,77 & --- & 21,35 & --- \\
\hline Porcentajes & $76 \%$ & --- & $24 \%$ & --- & $100 \%$ & --- \\
\hline
\end{tabular}


Los rendimientos de raíces reservantes totales [RR-Tot (B)] -comercial y no comercial- fluctúan de 18,43 a 0,00 y promedio de 2,20 t/ha (Cuadro 11). ANVA 11 muestra diferencias altamente significativas entre clones; DUNCAN 11 indica que Toquecita ocupa el ler lugar con 18,43 t/ha, superando a todos los clones. Siguen Mohc, SR90.323, Tabón y CC-89.213, con 7,66; 4,33; 4,28 y $2,42 \mathrm{t} / \mathrm{ha}$, y son los cinco clones más productivos.

Luego se observa un 2do grupo formado por Kumala, DLP-2481 y Solapa (t), con 2,32 a 0,35 t/ha. Finalmente se observa un 3 er grupo formado por trece clones con rendimientos de 0,89 a $0,0 \mathrm{t} / \mathrm{ha}$; siendo estadísticamente iguales.
Se resalta que DLP-90052 (máximo productor de follaje) no produce raíces reservantes $(0,00 \mathrm{t} / \mathrm{ha})$, ocupando la última posición, contrario al 1er lugar que ocupa en producción de follaje.

Rendimiento comparativo de Raíces Reservantes Total en (A) y (B) (t/ha).

Los rendimientos comparativos de raíces reservantes total (comercial y no comercial) en las franjas (A) y (B), se muestra en el Cuadro 12.

Tabla No 11. Rendimiento Comparativo de Raíces Total (t/ha) en (A) y (B).

\begin{tabular}{|c|c|c|c|c|}
\hline \multirow{2}{*}{$\begin{array}{c}\text { Clones } \\
\text { (Tratamiento } \\
\text { s) }\end{array}$} & \multicolumn{2}{|c|}{ Total (A1+A2) } & \multicolumn{2}{|c|}{ Total (B) } \\
\hline & $\begin{array}{l}\text { RR-Tot } \\
\text { ANVA } 8\end{array}$ & $\begin{array}{c}\text { RR-Tot } \\
\text { DUNCAN } 8\end{array}$ & RR-Tot & $\begin{array}{l}\text { RR-Tot } \\
\text { DUNCAN } 11\end{array}$ \\
\hline Toquecita & 7,30 & a & 18,43 & a \\
\hline Mohc & 4,03 & b & 7,66 & b \\
\hline Tabón & 1,96 & c & 4,61 & c \\
\hline SR-90.323 & 2,13 & c & 4,33 & c \\
\hline CC-89.213 & 1,00 & $d$ & 2,48 & $d$ \\
\hline Kumala & 0,50 & ef & 2,32 & de \\
\hline DLP-2481 & 0,74 & de & 1,60 & ef \\
\hline Solapa (t) & 0,48 & ef & 1,39 & $\mathrm{fg}$ \\
\hline Tipo 3 & 0,33 & $\mathrm{fg}$ & 0,89 & fgh \\
\hline Pikis & 0,35 & $\mathrm{fg}$ & 0,85 & fgh \\
\hline Yema huevo & 0,50 & ef & 0,63 & gh \\
\hline Unknown & 0,24 & $\mathrm{fg}$ & 0,57 & gh \\
\hline DLP-2462 & 0,27 & $\mathrm{fg}$ & 0,35 & h \\
\hline DLP-3548 & 0,00 & g & 0,00 & h \\
\hline DLP-90052 & 0,00 & g & 0,00 & h \\
\hline Helena & 0,00 & $g$ & 0,00 & h \\
\hline Dulce & 0,00 & $g$ & 0,00 & $\mathrm{~h}$ \\
\hline Acaro & 0,00 & $g$ & 0,00 & h \\
\hline Calabacito & 0,00 & $g$ & 0,00 & $\mathrm{~h}$ \\
\hline Morado & 0,00 & $g$ & 0,00 & $\mathrm{~h}$ \\
\hline Mojave & 0,00 & $g$ & 0,00 & $\mathrm{~h}$ \\
\hline Promedios & 0,94 & -- & 2,20 & -- \\
\hline C.V. (\%) & 22,15 & --- & 21,35 & --- \\
\hline Porcentaje & $43 \%$ & --- & $100 \%$ & -- \\
\hline
\end{tabular}


El rendimiento promedio de follaje en la franja (B) es de 2,20 t/ha (100\%) con corte único, frente al rendimiento en franja (A) de 0,94 t/ha (43\%) con dos cortes (A1 y A2).

En ambas franjas (A) y (B) destaca Toquecita como el máximo productor de raíces reservantes.

Globalmente se puede concluir que el bajo rendimiento total de raíces reservantes en la franja (A) (43\%) debido a los dos cortes de follaje A1 y A2; comparado con el rendimiento en la franja (B) (100\%) con corte único (Cuadro 12).

Al respecto, Llanos (1994) encontró que el corte de follaje a los 120 días es el más adecuado cuando se tiene por finalidad producir raíces reservantes.

Si la finalidad es producir follaje, se empezará a los 105 días con un intervalo de un mes hasta la cosecha.

Además el análisis indica que el corte a los 120 días reporta una mayor rentabilidad; en términos generales el follaje para venta representa un 25\% y las raíces un $75 \%$ del valor económico que deja el cultivo.

Buendía (1993) menciona a Kiarie (1988) que encontró correlación genotípica y fenotípica elevadas entre número de raíces y rendimiento de raíces.

El peso y la longitud de follaje no se correlacionan ni genotípica ni fenotípicamente con el rendimiento de raíz.

Esto significa que las características consideradas son independientes. Igualmente menciona a Li (1965), que encontró correlaciones positivas y negativas entre las características del follaje y las raíces.
La más importante de las correlaciones negativas fue entre i) peso total y número de raíces y ii) peso total de raíces con el peso total de follaje.

Consecuentemente es posible manifestar que la mayor producción de follaje reduce (limita) la producción de raíces reservantes, o sea la mayor o menor producción de follaje es independiente de la mayor o menor producción de raíces.

Consolidado de Rendimientos Totales de Follaje y Raíces A y B (t/ha)

El consolidado de rendimientos totales de follaje y raíces se presentan en el Cuadro 13.

Se observa que los rendimientos totales de follaje en la franja (A) fluctúan de 93,09 a 41,36 y promedio de 59,21 t/ha; destacan DLP-90025, Mojave y Morado con rendimientos de 93,09; 83,83; y $71,72 \mathrm{t} / \mathrm{ha}$, siendo los tres clones de mayor rendimiento, y en la franja (B) fluctúan de 49,44 a 19,03 y promedio de 30,09 t/ha. Destacan DLP2462 con 49,44 t/ha.

Los rendimientos totales de raíces reservantes en franja (A) fluctúan de 7,30 a 0,00 y promedio de $0,94 \mathrm{t} / \mathrm{ha}$.

Destacan Toquecita, Mohc y SR-90.323 con rendimientos de 7,30; 4,03 y 2,13 t/ha, siendo los tres clones más rendidores de raíces reservantes, y en franja (B) fluctúa de 18,43 a 0,00 y promedio de 2,20 t/ha, destacan Toquecita, Mohc y Tabón con 18,$43 ; 7,66$ y $4,61 \mathrm{t} / \mathrm{ha}$.

Se observa que DLP-90025, Mojave y Morado no producen raíces reservantes y DLP-2462 logra rendimientos de 0,27 y $0,35 \mathrm{t} /$ ha en $(\mathrm{A})$ y (B) (Tabla 12). 
Tabla $N^{\circ}$ 12. Rendimientos Totales Consolidados de Follaje y Raíces en (A) y (B) (t/ha)

\begin{tabular}{ccccc}
$\begin{array}{c}\text { Clones } \\
\text { Tratamiento }\end{array}$ & $\begin{array}{c}\text { FOLLAJE } \\
\text { TOTAL }(\mathbf{A}) \\
\text { (t/ha) }\end{array}$ & $\begin{array}{c}\text { FOLLAJE } \\
\text { TOTAL (B) } \\
\text { (t/ha) }\end{array}$ & $\begin{array}{c}\text { RAICES } \\
\text { TOTAL (A) } \\
\text { (t/ha) }\end{array}$ & $\begin{array}{c}\text { RAICES } \\
\text { TOTAL (B) } \\
\text { (t/ha) }\end{array}$ \\
\hline DLP-90052 & 93,09 & 27,47 & 0,00 & 0,00 \\
Mojave & 83,83 & 46,79 & 0,00 & 0,00 \\
Morado & 71,72 & 41,19 & 0,00 & 0,00 \\
DLP-2462 & 68,45 & 49,44 & 0,27 & 0,35 \\
SR-90.323 & 63,53 & 33,26 & 2,13 & 4,33 \\
Solapa (t) & 63,25 & 31,11 & 0,48 & 1,39 \\
DLP-3548 & 60,73 & 27,40 & 0,00 & 0,00 \\
Calabacito & 59,81 & 32,91 & 0,00 & 0,00 \\
Acaro & 59,38 & 37,41 & 0,00 & 0,00 \\
Dulce & 58,29 & 19,03 & 0,00 & 0,00 \\
DLP-2481 & 57,92 & 21,92 & 0,74 & 1,60 \\
Kumala & 57,72 & 31,09 & 0,50 & 2,32 \\
Unknown & 57,64 & 31,69 & 0,24 & 0,57 \\
Mohc & 56,64 & 32,69 & 4,03 & 7,66 \\
Tipo 3 & 54,86 & 23,98 & 0,33 & 0,89 \\
Tabón & 52,86 & 16,97 & 1,96 & 4,61 \\
Yema huevo & 50,73 & 20,34 & 0,50 & 0,63 \\
Helena & 47,34 & 40,18 & 0,00 & 0,00 \\
CC-89.213 & 42,67 & 23,05 & 1,00 & 2,48 \\
Toquecita & 41,50 & 19,59 & $\mathbf{7 , 3 0}$ & 18,43 \\
Pikis & 41,36 & 24,24 & 0,35 & 0,85 \\
Promedios & $\mathbf{5 9 , 2 1}$ & $\mathbf{3 0 , 0 8}$ & $\mathbf{0 , 9 4}$ & $\mathbf{2 , 2 0}$ \\
Porcentaje & $\mathbf{1 9 7 \%}$ & $\mathbf{1 0 0 \%}$ & $\mathbf{4 3 \%}$ & $\mathbf{1 0 0 \%}$ \\
\hline & & & &
\end{tabular}

\section{Determinación de la relación raíz/follaje $(\mathrm{R} / \mathrm{F})$}

Los resultados obtenidos de la Relación Raíces/Follaje (R/F) proporcionan los índices entre 1,10 y 0,0 (Tabla 13), y solo Toquecita califica como único clon Doble Propósito y los 20 clones restantes califican como Forrajeras, data concordante con los resultados de León-Velarde (2003).

Este importante índice de calidad coadyuva a la mejor calificación del clon Toquecita como clon promisorio de doble propósito con buenos rendimientos. 
Tabla $N^{\circ} 13$. Determinación de la relación raíz/follaje $(\mathrm{R} / \mathrm{F})$

\begin{tabular}{ccccc}
$\begin{array}{c}\text { Clones } \\
\text { Tratamiento }\end{array}$ & $\begin{array}{c}\text { M.S. } \\
\text { FOLLAJE } \\
\text { (t/ha) }\end{array}$ & $\begin{array}{c}\text { M.S. } \\
\text { RACES } \\
\text { (t/ha) }\end{array}$ & $\begin{array}{c}\text { Relación } \\
\mathbf{( R / F )}\end{array}$ & Aptitud \\
Toquecita & $\mathbf{3 , 9 8}$ & $\mathbf{4 , 3 6}$ & $\mathbf{1 , 1 0}$ & $\begin{array}{c}\text { Doble } \\
\text { Propósito }\end{array}$ \\
Tabón & 3,33 & $\mathbf{1 , 2 6}$ & $\mathbf{0 , 3 8}$ & Forrajera \\
Mohc & 7,01 & 1,69 & $\mathbf{0 , 2 4}$ & Forrajera \\
SR-90.323 & 8,71 & 1,01 & $\mathbf{0 , 1 2}$ & Forrajera \\
Kumala & 7,86 & 0,72 & $\mathbf{0 , 0 9}$ & Forrajera \\
CC-89.213 & 8,02 & 0,62 & $\mathbf{0 , 0 8}$ & Forrajera \\
Tipo 3 & 5,22 & 0,26 & $\mathbf{0 , 0 5}$ & Forrajera \\
Solapa (t) & $\mathbf{5 , 5 7}$ & $\mathbf{0 , 2 8}$ & $\mathbf{0 , 0 5}$ & Forrajera \\
DLP-2481 & 6,27 & 0,31 & $\mathbf{0 , 0 5}$ & Forrajera \\
Pikis & 6,30 & 0,18 & $\mathbf{0 , 0 3}$ & Forrajera \\
Yema huevo & 5,09 & 0,13 & $\mathbf{0 , 0 2}$ & Forrajera \\
Unknown & 7,73 & 0,10 & $\mathbf{0 , 0 1}$ & Forrajera \\
DLP-2462 & 9,39 & 0,09 & $\mathbf{0 , 0 1}$ & Forrajera \\
Helena & 9,38 & 0,00 & $\mathbf{0 , 0 0}$ & Forrajera \\
Morado & 9,36 & 0,00 & $\mathbf{0 , 0 0}$ & Forrajera \\
Mojave & 9,36 & 0,00 & $\mathbf{0 , 0 0}$ & Forrajera \\
Acaro & 9,35 & 0,00 & $\mathbf{0 , 0 0}$ & Forrajera \\
DLP-3548 & 8,97 & 0,00 & $\mathbf{0 , 0 0}$ & Forrajera \\
Calabacito & 8,23 & 0,00 & $\mathbf{0 , 0 0}$ & Forrajera \\
DLP-90052 & 7,77 & 0,00 & $\mathbf{0 , 0 0}$ & Forrajera \\
Dulce & 4,76 & 0,00 & $\mathbf{0 , 0 0}$ & Forrajera \\
Promedio & $\mathbf{7 , 2 2}$ & $\mathbf{0 , 5 2}$ & $\mathbf{0 , 1 1}$ & --- \\
& & & & \\
\hline
\end{tabular}

\section{Evaluación de clones por agricultores líderes}

Los resultados de la calificación de los clones por los agricultores líderes se muestran en el Anexo 3. Acorde a lo establecido en CIP-CARE (2002), éstos se toman como referenciales y complementarios a los valores obtenidos en la investigación.

La escala de evaluación para follaje (utilizada por los agricultores) fue B: Bueno, R: Regular y M: Malo, y para raíces reservantes, F: Forrajera, DP: Doble Propósito y R: Raicera.

Para ello previamente se capacitó a los agricultores en el uso de tarjetas y en forma sucesiva pasaron por las U.E. y colocaron dos tarjetas/clon. Se indica que los productores líderes participantes en la evaluación mostraron marcada preferencia por clones raiceros siendo una experiencia inédita y manifestaron mucho entusiasmo y satisfacción al calificar.

Parámetros de calidad (PCd):

Rendimientos de materia seca y proteína en follaje (t/ha)

Los rendimientos de materia seca (MS) en follaje fluctúan de 9,39 a 3,33 y promedio 7,22 t/ha (Tabla 14). Se observa que 12 clones superan al promedio, destacan los clones DLP-2462, Helena y Acaro, que producen 9,39; 9,38 y 9,35 t/ha respectivamente. Solapa $(\mathrm{t})$ y Toquecita rinden 5,57 y 3,98 t/ha, ambos menores al promedio. 
Tabla $N^{\circ} 14$. Rendimientos de materia seca y proteína en follaje ( $\left.t / h a\right)$

$\begin{array}{cccccc}\begin{array}{c}\text { Clones } \\ \text { Tratamiento }\end{array} & \text { Follaje (t/ha) } & \text { M.S. \% } & \begin{array}{c}\text { M.S. } \\ \text { (t/ha) }\end{array} & \begin{array}{c}\text { Proteína } \\ -1 \%\end{array} & \begin{array}{c}\text { Proteína } \\ \text { (t/ha) }\end{array} \\ \text { Helena } & 40,18 & 23,33 & 9,38 & 18,27 & 7,34 \\ \text { DLP-2462 } & 49,44 & 18,99 & 9,39 & 13,27 & 6,56 \\ \text { SR-90.323 } & 33,26 & 26,19 & 8,71 & 19,33 & 6,43 \\ \text { Acaro } & 37,41 & 25,00 & 9,35 & 15,59 & 5,83 \\ \text { Solapa (t) } & 31,11 & 17,89 & 5,57 & 14,24 & 4,43 \\ \text { Kumala } & 31,09 & 25,29 & 7,86 & 11,84 & 3,68 \\ \text { DLP-90052 } & 27,47 & 28,29 & 7,77 & 13,06 & 3,59 \\ \text { DLP-2481 } & 21,92 & 28,62 & 6,27 & 16,01 & 3,51 \\ \text { Mohc } & 32,69 & 21,43 & 7,01 & 10,50 & 3,43 \\ \text { Toquecita } & 19,59 & 20,31 & 3,98 & 14,88 & 2,91 \\ \text { Yema huevo } & 20,34 & 25,00 & 5,09 & 15,05 & 2,86 \\ \text { Morado } & 41,19 & 22,73 & 9,36 & \text { No selectos } \\ \text { Mojave } & 46,79 & 20,00 & 9,36 & \text { No selectos } \\ \text { DLP-3548 } & 27,40 & 32,75 & 8,97 & \text { No selectos } \\ \text { Calabacito } & 32,91 & 25,00 & 8,23 & \text { No selectos } \\ \text { CC-89.213 } & 23,05 & 34,81 & 8,02 & \text { No selectos } \\ \text { Unknown } & 31,69 & 24,39 & 7,73 & \text { No selectos } \\ \text { Pikis } & 24,24 & 26,00 & 6,30 & \text { No selectos } \\ \text { Tipo 3 } & 23,98 & 21,77 & 5,22 & \text { No selectos } \\ \text { Dulce } & 19,03 & 25,00 & 4,76 & \text { No selectos } \\ \text { Tabón } & 16,97 & 19,61 & 3,33 & \text { No selectos } \\ \text { Promedios } & 30,08 & 24,40 & 7,22 & 14,73 & 4,60 \\ & & & & & \end{array}$

Los rendimientos de materia seca foliar obtenidos son semejantes a los 8,06 -2,42 t/ha obtenidos en San Ramón por León-Velarde (2003) y mucho menores que 20,40 -10,10 t/ha obtenidos en Huaral por Bravo (2002) citado por León-Velarde (2003).

Los rendimientos de proteína en follaje fluctúan de 7,34 a 2,86 y promedio 4,60 t/ha (Tabla 14 ).

Destacan Helena, DLP-2462 y SR-90.323 con 7,$34 ; 6,56$ y $6,43 \mathrm{t} / \mathrm{ha}$, superiores al promedio; Solapa $(\mathrm{t})$, rinde $4,43 \mathrm{t} / \mathrm{ha}$.
Rendimientos de materia seca y proteína en raíces reservantes (t/ha)

Los rendimientos de materia seca en raíces reservantes fluctúa de 4,36 a 0,00 y promedio de 0,52 t/ha (Tabla 15).

Destaca Toquecita el cual rinde 4,36 t/ha, 8,4 veces más que la media y Solapa $(\mathrm{t})$ rinde $0,28 \mathrm{t} / \mathrm{ha}$, solo $54 \%$ respecto al promedio.

Estos valores están dentro del rango de 11,29 0,84 t/ha en San Ramón reportados por León-Velarde (2003). 
Tabla $N^{\circ} 15$. Rendimientos de materia seca y proteína en raíces reservantes (t/ha)

$\begin{array}{cccccc}\begin{array}{c}\text { Clones } \\ \text { Tratamiento }\end{array} & \begin{array}{c}\text { Rdto Raíces } \\ \text { (t/ha) }\end{array} & \text { M.S. (\%) } & \begin{array}{c}\text { Rdto M.S. } \\ \text { (t/ha) }\end{array} & \begin{array}{c}\text { RdtoA32D32 } \\ \text { Proteína (\%) } \\ \text { (2) }\end{array} & \begin{array}{c}\text { 4:F327 } \\ \text { Proteína } \\ \text { (t/ha) }\end{array} \\ \text { Toquecita } & 18,43 & 23,67 & \mathbf{4 , 3 6} & \mathbf{6 , 8 3} & \mathbf{1 , 2 6} \\ \text { Solapa (t) } & \mathbf{1 , 3 9} & 19,89 & \mathbf{0 , 2 8} & \mathbf{6 , 1 3} & \mathbf{0 , 0 9} \\ \text { Mohc } & 7,66 & 22,13 & \mathbf{1 , 6 9} & \text { produce pocas raíces } \\ \text { Tabón } & 4,61 & 27,30 & \mathbf{1 , 2 6} & \text { produce pocas raíces } \\ \text { SR-90.323 } & 4,33 & 23,38 & \mathbf{1 , 0 1} & \text { produce pocas raíces } \\ \text { Kumala } & 2,32 & 31,19 & \mathbf{0 , 7 2} & \text { produce muy pocas raíces } \\ \text { CC-89.213 } & 2,48 & 24,84 & \mathbf{0 , 6 2} & \text { produce muy pocas raíces } \\ \text { DLP-2481 } & 1,60 & 19,13 & \mathbf{0 , 3 1} & \text { produce muy pocas raíces } \\ \text { Tipo 3 } & 0,89 & 29,21 & \mathbf{0 , 2 6} & \text { produce muy pocas raíces } \\ \text { Pikis } & 0,85 & 21,67 & \mathbf{0 , 1 8} & \text { produce muy pocas raíces } \\ \text { Yema huevo } & 0,63 & 20,00 & \mathbf{0 , 1 3} & \text { produce muy pocas raíces } \\ \text { Unknown } & 0,57 & 18,22 & \mathbf{0 , 1 0} & \text { produce muy pocas raíces } \\ \text { DLP-2462 } & 0,35 & 26,67 & \mathbf{0 , 0 9} & \text { produce muy pocas raíces } \\ \text { Helena } & 0,00 & 0,00 & \mathbf{0 , 0 0} & \text { no produce raíces } \\ \text { Morado } & 0,00 & 0,00 & \mathbf{0 , 0 0} & \text { no produce raíces } \\ \text { Mojave } & 0,00 & 0,00 & \mathbf{0 , 0 0} & \text { no produce raíces } \\ \text { Acaro } & 0,00 & 0,00 & \mathbf{0 , 0 0} & \text { no produce raíces } \\ \text { DLP-3548 } & 0,00 & 0,00 & \mathbf{0 , 0 0} & \text { no produce raíces } \\ \text { Calabacito } & 0,00 & 0,00 & \mathbf{0 , 0 0} & \text { no produce raíces } \\ \text { DLP-90052 } & 0,00 & 0,00 & \mathbf{0 , 0 0} & \text { no produce raíces } \\ \text { Dulce } & 0,00 & 0,00 & \mathbf{0 , 0 0} & \text { no produce raíces } \\ \text { Promedios } & & \mathbf{1 4 , 6 3} & \mathbf{0 , 5 2} & \\ & & & & \end{array}$

Los rendimientos de proteína en raíces reservantes son de 1,26 y $0,09 \mathrm{t} /$ ha para Toquecita y Solapa $(\mathrm{t})$.

Se resalta el contenido la proteína en Toquecita que produce 14 veces más que Solapa $(\mathrm{t})$, este resultado aporta a la mejor calificación de Toquecita como doble propósito.

Evaluación del ataque Plaga-Pudrición-Cracking (PPC)

Los resultados promedios del ataque de Plaga-Pudrición-Cracking son 2-3-2 (Tabla 16) indican que se cosecharon raíces reservantes con leve presencia del ataque de plagas, pudriciones y rajaduras (cracking).
El mínimo ataque de plagas observadas fueron el gorgojo del camote Euscepes sp, y gusanos de tierra, mínima pudrición y rajaduras; ello significa que la aplicación de buenas prácticas agrícolas (BPA) y rotación de cultivos en el periodo experimental dieron resultados positivos.

Debe indicarse que en el ensayo no se realizó ninguna aplicación de agroquímicos, por lo que los valores de 2-3-2, obtenidos se puede considerar como mínimos y raíces reservantes aceptables para alimentación humana 
Tabla $N^{\circ}$ 16. Evaluación del ataque Plaga-Pudrición-Cracking (PPC)

\begin{tabular}{cccc}
$\begin{array}{c}\text { Clones } \\
\text { Tratamiento }\end{array}$ & Plaga & Pudrición & Cracking \\
\hline Solapa (t) & $\mathbf{4}$ & $\mathbf{4}$ & $\mathbf{4}$ \\
CC-89.213 & 2 & 4 & 4 \\
Pikis & 3 & 4 & 3 \\
Yema huevo & 2 & 4 & 4 \\
Tabón & 3 & 4 & 3 \\
DLP-90052 & 2 & 3 & 4 \\
Morado & 2 & 4 & 3 \\
Tipo-3 & 2 & 3 & 4 \\
Toquecita & $\mathbf{3}$ & $\mathbf{3}$ & $\mathbf{2}$ \\
DLP-2481 & 1 & 4 & 3 \\
Mohc & 2 & 4 & 2 \\
Mojave & 2 & 3 & 3 \\
SR-90.323 & 3 & 2 & 2 \\
Kumala & 2 & 2 & 2 \\
DLP-2462 & 1 & 2 & 2 \\
Helena & 1 & 2 & 2 \\
Dulce & 1 & 2 & 2 \\
Unknown & 1 & 2 & 2 \\
DLP-3548 & 1 & 2 & 1 \\
Acaro & 1 & 1 & 1 \\
Calabacito & 1 & 1 & 1 \\
Promedio & $\mathbf{2}$ & $\mathbf{3}$ & $\mathbf{2}$ \\
\hline & & &
\end{tabular}

Tecnología tradicional y mejorada:

\section{Tecnología tradicional}

Las labores culturales de la Tecnología Tradicional aplicada por el agricultor-colaborador en su cultivo propio (clon Solapa y un solo corte de follaje) son ampliamente conocidas de siembra a cosecha, totalmente orientada a la produccion de camotes (raices reservantes), con 2 a 3 aplicaciones de fertilizantes foliares y mínimo aprovecha- miento del follaje no obstante la evidente escasez de forrajes en la zona para la alimentación de caprinos (tabla 17).

\section{Tecnología mejorada}

La Tecnología Mejorada aplicada en el ensayo está orientada principalmente a la producción de forraje y raíces y es conducido como Parcela Demostrativa con Toquecita. 
Tabla $\mathrm{N}^{\circ} \mathbf{1 7}$. Comparación de tecnologías tradicional y mejorada

\begin{tabular}{|c|c|c|}
\hline Actividades & $\begin{array}{l}\text { Tecnologia } \\
\text { Tradicional }\end{array}$ & $\begin{array}{l}\text { Tecnologia } \\
\text { Mejorada }\end{array}$ \\
\hline $\begin{array}{l}\text { Rotacion de } \\
\text { Cultivos }\end{array}$ & Indiferente & $\begin{array}{l}\text { Maíz-Camote- } \\
\text { Frijoles }\end{array}$ \\
\hline $\begin{array}{l}\text { Textura del } \\
\text { Terreno }\end{array}$ & $\begin{array}{l}\text { Cualquiera, } \\
\text { Orilleros }\end{array}$ & $\begin{array}{c}\text { Francos Y Fco- } \\
\text { Arenosos }\end{array}$ \\
\hline Preparacion & $\begin{array}{l}\text { Manual Con } \\
\text { Palana }\end{array}$ & $\begin{array}{c}\text { Aradura, Cruza, } \\
\text { Re-Cruza Y }\end{array}$ \\
\hline Terreno & $\begin{array}{c}\text { "Tareas } 200 \\
\text { M2/Día/Jornal". }\end{array}$ & $\begin{array}{l}\text { Surcado Con } \\
\text { Caballo }\end{array}$ \\
\hline Surcado & No Realizan & $\begin{array}{c}\text { 1,0 M, Entre } \\
\text { Surcos }\end{array}$ \\
\hline Distanciamiento & $\begin{array}{c}\text { Camellones O } \\
\text { Huecos }\end{array}$ & $\begin{array}{c}\text { Pp: } 0.25-0,30 \\
M\end{array}$ \\
\hline Abonamiento & $\begin{array}{l}\text { En Siembra O } \\
\text { Después }\end{array}$ & $\begin{array}{l}\text { En Preparación } \\
\text { De Terreno }\end{array}$ \\
\hline N-P-K & $\begin{array}{c}\text { Aplica } 1,0 \mathrm{~T} / \mathrm{Ha} \\
\text { Estiércol Seco } \\
\text { Caprino (15-15- } \\
30)\end{array}$ & $\begin{array}{c}5,0 \mathrm{~T} / \mathrm{Ha} \\
\text { Estiércol } \\
\text { Compostado De } \\
\text { Caprino; } 190-80- \\
60 .\end{array}$ \\
\hline $\begin{array}{l}\text { Epocas De } \\
\text { Siembra }\end{array}$ & Ene-Mar & Todo El Año \\
\hline Siembra & $\begin{array}{c}\text { 3-4 } \\
\text { Esquejes/Hoyo }\end{array}$ & $\begin{array}{c}1 \text { Esqueje / } \\
\text { Hoyo }\end{array}$ \\
\hline $\begin{array}{l}\text { Densidad de } \\
\text { Plantas }\end{array}$ & 100,000 Plantas & $\begin{array}{c}40,000-50,000 \\
\text { Plantas }\end{array}$ \\
\hline $\begin{array}{l}\text { Edad de } \\
\text { Esquejes }\end{array}$ & Cualquier Edad & De 80 A 90 Días \\
\hline Variedades & Solapa: Tardía & $\begin{array}{l}\text { Toquecita Doble- } \\
\text { Propósito }\end{array}$ \\
\hline Deshierbos & 1 Aleatorio, & $\begin{array}{c}1,2 \text { Y } 3 \text { A Los } \\
21,75,120 \text { Días }\end{array}$ \\
\hline Riegos & $\begin{array}{l}\text { Riego Aleatorio } \\
\text { Y/O Lluvia } \\
\text { Complementaria }\end{array}$ & $\begin{array}{c}5 \text { Riegos } \\
\text { (Aprox. } 5000 \\
\text { M3/Ha/Campañ } \\
\text { a) }\end{array}$ \\
\hline
\end{tabular}

Aporques No Realizan A Los 40 Días 


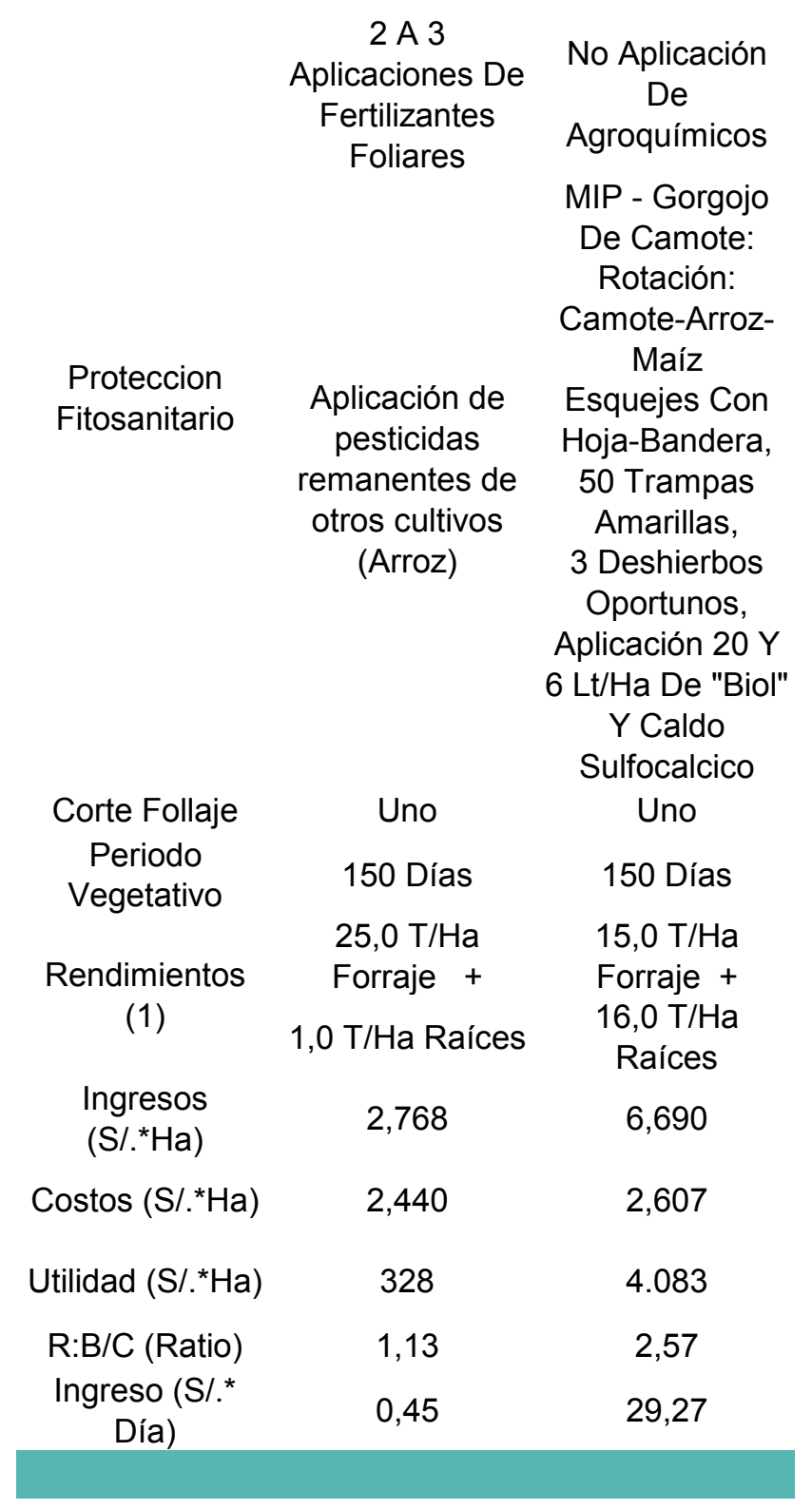

Toma como base las labores culturales de la tecnología tradicional, así como la introducción de Buenas Prácticas Agrícolas (BPA) y labores tendientes al MIP-camote.

Se debe enfatizar que no se realizó (0) aplicación de agroquímicos y se puntualizan en:

1. Mejor preparación del terreno

2. Siembra en surcos y plantación de un solo esqueje/hoyo

3. Aplicación de 190-80-60 kg/ha NPK como estiércol de cabra (basado en análisis)

4. Nueva variedad: Toquecita doble propósito

5. Tres deshierbos a los 20, 70 y 120 dds y cinco riegos oportunos
6. Instalación de 50 trampas amarillas

7. Corte de follaje (En franja A1 (inicial) y A2 (rebrote).

8. Protección fitosanitaria preventiva con aplicaciones de biocidas; 20 lt/ha de biol más $6 \mathrm{lt} / \mathrm{ha}$ de caldo sulfocálcico aplicaciones tendientes al MIP-camote.

\section{Resultados de costos de producción}

Los costos de producción toma todos los costos de las labores de cultivo y para su análisis se ha elaborado una Matriz de Costos de Producción de Camote (en Excel), se calcula con rendimientos netos (90\% del forraje (-10\% mermas/corte y 
carguío) y solo con las raíces reservantes comerciales (camote comestibles), luego se ha corrido la matriz para todas las opciones y analizado los costos de producción en las franjas A y B.

Detalle en Anexo 7.
Costos de producción de clones más destacados (CLONES TOP)

Los resultados de los costos de producción de los clones más destacados (clones top) DLP-90025, DLP-2462 (forrajeros), Toquecita (Doble propósito) y Solapa (testigo). Tabla18.

Tabla $\mathrm{N}^{\circ}$ 18. Comparación de tecnologías tradicional y mejorada

\begin{tabular}{|c|c|c|c|c|c|}
\hline \multicolumn{6}{|c|}{ CLON: DLP-90052 (Forrajera) } \\
\hline Ord & Rubros & Unid & Franja $(A)$ & Franja (B) & $\%$ \\
\hline 1 & $\begin{array}{l}\text { Alquiler } \\
\text { terreno }\end{array}$ & ha/camp & 300 & 300 & 14 \\
\hline 2 & Mano de obra & jornal & 528 & 480 & 25 \\
\hline 3 & $\begin{array}{c}\text { Tracción y } \\
\text { transporte } \\
\text { animal }\end{array}$ & día/cab & 330 & 330 & 16 \\
\hline 4 & $\begin{array}{c}\text { Semilla, } \\
\text { agua, } \\
\text { insumos } \\
\text { Sacos }\end{array}$ & global & 562 & 562 & 27 \\
\hline 5 & $\begin{array}{c}\text { plásticos } 2 \mathrm{da} \\
+ \text { piolas }\end{array}$ & mallas & 0 & 0 & 0 \\
\hline 6 & $\begin{array}{l}\text { Interés/mes } \\
\text { de insumos * }\end{array}$ & $4 \%$ & 0 & 0 & 0 \\
\hline 7 & $\begin{array}{c}\text { Imprevistos } \\
5 \% \text { CD. } \\
\text { Asistencia }\end{array}$ & glb & 121 & 120,8 & 6 \\
\hline \multirow[t]{2}{*}{8} & $\begin{array}{l}\text { Técnica (5 } \\
\text { visitas) }\end{array}$ & día/hh & 250 & 250 & 12 \\
\hline & Totales & -.- & 2091 & 2043 & 100 \\
\hline
\end{tabular}

\section{CLON DLP-2462 (Forrajera)}

$\begin{array}{ll}1 & \text { Alquiler terreno } \\ 2 & \text { Mano de obra } \\ 3 & \text { in y transporte animal } \\ 4 & \text { illla, agua, insumos } \\ 5 & \text { plásticos } 2 \text { da + piolas } \\ 6 & \text { is/mes de insumos * } \\ 7 & \text { previstos } 5 \% \text { CD. } \\ 8 & \text { icia Técnica (5 visitas) } \\ . & \text { Totales }\end{array}$

$\begin{array}{cc}\text { ha/camp } & 300 \\ \text { jornal } & 504 \\ \text { día/cab } & 330 \\ \text { global } & 562 \\ \text { mallas } & 0 \\ 4 \% & 0 \\ \text { glb } & 121 \\ \text { día/hh } & 250 \\ \text {-.- } & \mathbf{2 0 6 7}\end{array}$

300

15

$480 \quad 24$

$330 \quad 16$

$562 \quad 27$

$0 \quad 0$

$0 \quad 0$

$120,8 \quad 6$

$250 \quad 12$

2043

100 


\begin{tabular}{|c|c|c|c|c|c|}
\hline \multicolumn{6}{|c|}{ CLON TOQUECITA (Doble propósito) } \\
\hline 1 & Alquiler terreno & ha/camp & 300 & 300 & 12 \\
\hline 2 & Mano de obra & jornal & 768 & 684 & 30 \\
\hline 3 & $\begin{array}{l}\text { Tracción y } \\
\text { transporte } \\
\text { animal }\end{array}$ & día/cab & 540 & 540 & 21 \\
\hline 4 & $\begin{array}{l}\text { Semilla, agua, } \\
\text { insumos }\end{array}$ & global & 562 & 562 & 22 \\
\hline 5 & $\begin{array}{c}\text { Sacos plásticos } \\
2 \mathrm{da}+\text { piolas }\end{array}$ & mallas & 50 & 150 & 2 \\
\hline 6 & $\begin{array}{l}\text { Interés/mes de } \\
\text { insumos * }\end{array}$ & $4 \%$ & 0,0 & 0 & 0 \\
\hline 7 & $\begin{array}{c}\text { Imprevistos 5\% } \\
\text { CD. } \\
\text { Asistencia }\end{array}$ & glb & 121 & 120,8 & 5 \\
\hline \multirow[t]{2}{*}{8} & $\begin{array}{l}\text { Técnica (5 } \\
\text { visitas) }\end{array}$ & día/hh & 250 & 250 & 10 \\
\hline & Totales &.-- & 2591 & 2607 & 100 \\
\hline
\end{tabular}

\begin{tabular}{|c|c|c|c|c|c|}
\hline \multicolumn{6}{|c|}{ CLON- SOLAPA (Testigo). } \\
\hline 1 & Alquiler terreno & ha/camp & 300 & 300 & 12 \\
\hline 2 & Mano de obra & jornal & 648 & 600 & 27 \\
\hline 3 & Tracción y transporte animal & día/cab & 540 & 540 & 22 \\
\hline 4 & Semilla, agua, insumos & global & 562 & 562 & 23 \\
\hline 5 & Sacos plásticos 2 da + piolas & mallas & 0 & 10 & 0 \\
\hline 6 & Interés/mes de insumos * & $4 \%$ & 0,0 & 0 & 0 \\
\hline 7 & Imprevistos 5\% CD. & glb & 121 & 121 & 5 \\
\hline \multirow[t]{2}{*}{8} & Asistencia Técnica (5 visitas) & día/hh & 250 & 250 & 10 \\
\hline & Totales &.-- & 2421 & 2440 & 100 \\
\hline
\end{tabular}




\section{Consolidado de costos de producción de clones top}

El consolidado de los costos de producción de clones top; DLP-90052, DLP-2462, Toquecita, y Solapa (t), se expone en el cuadro 20 y anexo 7 , los que se detallan:

Tabla $N^{\circ} 19$. Consolidado de costos de producción de clones top (S/.* ha).

\begin{tabular}{ccc}
\hline CLONES & Franja A & Franja B \\
DLP-90025 - FORRAJERA & \\
RENDIMIENTOS & 83.781 & 24.723 \\
INGRESOS & 7285 & 2150 \\
COSTOS & 2091 & 2043 \\
UTILIDAD & 5195 & 107 \\
R:B/C & 3,48 & 1,05 \\
DLP-2462 - FORRAJERA & \\
RENDIMIENTOS & 61,605 & 44,496 \\
INGRESOS & 5,357 & 3,869 \\
COSTOS & 2067 & 2043 \\
UTILIDAD & 3290 & 2039 \\
R:B/C & 2,59 & 1,89 \\
TOQUECITA - DOBLE PROPOSITO \\
RENDIMIENTOS & 43.15 & 33.978 \\
INGRESOS & 5181 & 6690 \\
COSTOS & 2591 & 2607 \\
UTILIDAD & 2590 & 4083 \\
R:B/C & 2,00 & 2,57 \\
SOLAPA - TESTIGO & \\
RENDIMIENTOS & 56.925 & 28 \\
INGRESOS & 4950 & 2768 \\
COSTOS & 2421 & 2440 \\
UTILIDAD & 2529 & 328 \\
R:B/C & 2,04 & 1,13 \\
\hline
\end{tabular}

\section{Costos de Producción por Tecnologías (S/.x ha)}

Los costos de producción comparativos de camote con Tecnología Tradicional (del agricultor) y Tecnología Mejorada (del investigador), con un corte "únicos" (tipo B) se muestran en el cuadro 21.
El mayor costo de producción con tecnología mejorada está imputado fundamentalmente a actividades de Buenas Prácticas Agrícolas (BPA) y protección fitosanitaria preventiva (sin aplicación de agroquímicos) tendientes al Manejo Integrado de Pestes de camote (MIP-camote). 
Tabla $\mathrm{N}^{\circ} 20$. Consolidado de costos de producción de clones top $\left(\mathrm{S} / .^{\star} \mathrm{ha}\right)$.

\begin{tabular}{|c|c|c|}
\hline Tecnologías & Tradicional & Mejorada \\
\hline Cultivo & Comercial & Experimental \\
\hline Clones & Solapa (t) & Toquecita \\
\hline \multirow{3}{*}{$\begin{array}{l}\text { Rendimientos } \\
\text { (t/ha) }\end{array}$} & Forraje: 25,0 & \multirow{3}{*}{$\begin{array}{l}\text { Forraje: } 15,0+ \\
\text { Camote: } 16,0\end{array}$} \\
\hline & + & \\
\hline & Camote: 01,0 & \\
\hline Ingresos (S/.) & 2.768 & 6.69 \\
\hline Costos (S/.) & 2440 & 2.607 \\
\hline Utilidad (S/.) & 328 & 4.083 \\
\hline Ratio $\mathrm{R}: \mathrm{B} / \mathrm{C}$ & 1,13 & 2,57 \\
\hline Ranking & 2do & 1ro \\
\hline
\end{tabular}

Los importes de costos de producción obtenidos son de S/. 2,440 (US\$ 737) y 2,607 (US\$ 787) para Tecnologías Tradicional y Mejorada son aceptables y algo mayores a US\$ 700/ha, reportados por Fonseca et al. (2002); quien indica que los agricultores consideran la importancia del camote por su bajo costo de producción y la mayor rentabilidad.

Condori (2016), indica que $\mathrm{R}: \mathrm{B} / \mathrm{C}=2,57$ de la Tecnología Mejorada, por cada nuevo sol invertido se obtiene ingresos de un nuevo sol cincuenta y siete céntimos, y con Tecnología Tradicional R: $\mathrm{B} / \mathrm{C}=1,13$ por cada nuevo sol invertido se obtiene trece céntimos.

\section{Análisis de costos de opciones productivas}

Adicionalmente a los costos de producción por tecnologías se ha realizado el análisis de costos de opciones productivas (directas y combinadas) en las franjas (A) y (B) de 4 clones: Forrajeros: DLP90052 y DLP-2462, Doble Propósito: Toquecita, y Solapa (t), identificándose 36 opciones productivas (8 directas y 28 combinadas).

\section{CONCLUSIONES}

1) En el ensayo se logró 27,50 (92\%) esquejes prendidos sin diferencias estadísticas entre los clones.

Las plantas mostraron Regular a Buen, Vigor-Uniformidad-Cobertura (VUC), lo que aseguró buen inicio y posterior nula a pobre floración de los clones.

2) Los rendimientos de follaje en la franja (A) (cortes A1 y A2) fluctuaron de 93,09 a 41,36 y promedio de 59,21 t/ha, destaca DLP-90052, con 93,09 t/ha, y en la franja (B) de 49,44 a 16,97 y promedio de $30,08 \mathrm{t} /$ ha (corte $\mathrm{B}$ ), con diferencias altamente significativas destacando DLP-2462 con 49,44 t/ha.

Solapa (t), logra 63,25 y $31,11 \mathrm{t} /$ ha en (A) y (B) respectivamente

3) El rendimiento de materia seca en follaje varía de 9,39 a 3,33 y promedio de 7,22 t/ha, destacando los clones DLP-2462 y Helena, con 9,39 y 9,38 $\mathrm{t} / \mathrm{ha}$, con los mayores contenidos de materia seca. Solapa (t), logró 5,57 t/ha.

4) El contenido de proteína en follaje osciló de 7,34 a 2,86 y 4,60 t/ha promedio. Destacan Helena y DLP-2462, con 7,34 y 6,56 t/ha. Solapa (t), logra 4,43 t/ha. 
Estos resultados permiten afirmar la buena calidad de los clones avanzados por su alto contenido de proteína que son $66 \%$ y $48 \%$ mayores que de Solapa ( $\mathrm{t}$ ).

5) Los rendimientos de raíces reservantes total -comercial y no comercial- en la franja (A) fluctúan de 7,30 a 0,00 y $0,94 \mathrm{t} /$ ha promedio; y en (B) de 18,43 a 0,00 y $2,20 \mathrm{t} /$ ha promedio, con diferencias estadísticas altamente significativas en ambas franjas.

En ambas franjas destaca visiblemente Toquecita con 7,30 y $18,43 \mathrm{t} /$ ha como el máximo productor de raíces reservantes; Solapa $(\mathrm{t})$ logra 0,48 y 1,39 $\mathrm{t} /$ ha en (A) y (B) respectivamente; ocho clones no producen raíces $(0.00 \mathrm{t} / \mathrm{ha})$. Se observa que el mayor rendimiento (+97\%) de follaje en la franja (A) con dos cortes incidió en la significativa reducción del rendimiento a $0,94 \mathrm{t} / \mathrm{ha}$ de raíces reservantes (43\%) en (A); respecto al rendimiento de $2,20 \mathrm{t} / \mathrm{ha}(100 \%)$ en la franja (B).

Existe correlación negativa entre el rendimiento de follaje y el rendimiento de raíces reservantes.

6) Los rendimientos de materia seca en raíces reservantes varío de 4,36 a 0,00, destacando Toquecita con 4,36 t/ha máximo rendimiento; Solapa (t) logró $0,28 \mathrm{t} / \mathrm{ha}$.

7) El contenido de proteína en raíces reservantes en Toquecita fue de 1,26 t/ha, lo que equivale a 14 veces más proteína que 0,09 t/ha de Solapa (t).

8) Toquecita con $\mathrm{R} / \mathrm{F}=1,10$ califica como único clon doble propósito, y los 20 clones restantes incluido Solapa $(t)$, son o tienen aptitud forrajera.

9) El ensayo ha permitido generar una tecnología de producción mejorada de camote doble propósito con el clon Toquecita, el cual rinde 15,0 t/ha de forraje en un corte y una atractiva cosecha de $16,0 \mathrm{t} /$ ha de raíces reservantes (camote comestible).
10) El costo de producción con la tecnología tradicional con el clon Solapa $(\mathrm{t})$, requiere una inversión de S/. 2,440/ha (US\$ 737,2), reporta una utilidad de S/. 328, y un R: B/C =1,13.

Por cada sol invertido se logra ingresos de solo trece céntimos.

11) El costo de producción con la tecnología mejorada con Toquecita, requiere una inversión de S/.2,607/ha (US\$ 789), reporta utilidad de S/. 4,083 ; $\mathrm{R}: \mathrm{B} / \mathrm{C}=2,57$; es decir por cada sol invertido se logra ingresos de un sol con cincuenta y siete céntimos.

Los superiores rendimientos de follaje y raíces reservantes (camote comestible), mayor contenido de proteína y los positivos índices económicos demuestran la alta rentabilidad de la nueva tecnología con Toquecita, calificada como clon promisorio de doble propósito; y se afirma que su adaptación en el ecosistema de bosque seco es técnicamente viable, económicamente rentable y social-ambientalmente sostenibles.

\section{RECOMENDACIONES}

1) Validar los rendimientos del clon Toquecita doble propósito como cultivo alternativo sostenible y ser incluido en la cédula de cultivos para su difusión y pronta adopción por los agricultores y capricultores de la macroregión norte.

2) Comunicar al Ministerio de Agricultura de la macroregión norte y afines la tecnología de producción mejorada con el clon Toquecita, para su difusión y pronta adopción por los agricultores y capricultores, la que asegura su viabilidad técnica, rentabilidad económica y sustentabilidad ambiental en el ecosistema bosque seco.

\section{REFERENCIAS BIBLIOGRÁFICAS}

BARRIGA, G.J. (1995). Evaluación del rendimiento y calidad nutritiva como alimento para cuyes. Tesis Magíster Scientiae UNA La Molina- Perú. 
BEAUFORT-MURPHY, H. (1994). Desarrollo de una variedad de camote (Ipomoea batatas) con amplia adaptación como nuevo cultivo forrajero perenne, ambientalmente sostenible. En: Resúmenes VIII Congreso Internacional de Sistemas Agropecuarios y su proyección al tercer milenio. Valdivia Chile.1994, p.17.v.22.

BARRIOS, J. R. y COLMENARES R. (1989). Potencialidad de la batata Ipomoea batatas (L) Lam.) como forraje verde. Alcance 38. Revista Facultad de Agronomía. U. C. V. Venezuela.

BUENDIA, T. S. (1993). Evaluación de germoplasma de camote (I. batatas (L.) Lam), con fines de selección, en el desarrollo de un programa de mejoramiento por adaptación y rendimiento. Tesis M. Sc. UNA La Molina - Lima, Perú. Pag.46.

BURGA, J. L. (1987). Situación del cultivo de camote en el Perú. En: Memorias del "Seminario sobre mejoramiento de la batata (Ipomoea batatas) en Latinoamérica”. Lima. Pág. 100 .

CALZADA, B.J. (1992). Métodos Estadísticos para la Investigación. Lima Perú.

CIP, (1992). Desarrollo de Productos de raíces y tubérculos. Vol. II - América Latina. CIP, CIAT, IITA, ICTA. Editores: Gregory J. Scott, et. al. Lima Perú.

CIP, (1996). Manual de manejo de germoplasma de batata o camote (Ipomoea batatas). Manual de Capacitación. Autores: C. Fonseca, J.P. Molina, E.E. Carey. Lima, Perú.

CIP-CARE, (2002). Guía para facilitar el desarrollo de escuelas de campo de agricultores. Lima, Perú.

CONDORI, A.C. (2015). Curso de Economía Agraria. Facultad de Economía y Planificación de la Universidad Nacional Agraria La Molina. Lima, Perú.

CUBA, S.A. (1998). Bosques Secos y Desertificación. Memorias del Seminario Internacional. INRENA Proyecto Algarrobo. Lambayeque-Perú.

DOMÍNGUEZ, P.L. (1992). Utilización del camote (Ipomoea batatas) en la alimentación de los cerdos. En: Desarrollo de productos de raíces y tubérculos, volumen 2. 1991 Lima, Perú, CIP. p. 111-120.

EL COMERCIO (2010). No solo con la papa: el Perú también es campeón del camote. http://elcomercio.pe/ gastronomia/peruana/no-solo-papa-peru-tambien-campeon-camote-noticia- 483804

FONSECA, C., R. Zuger, T. Walker y J. Molina. (2002). Estudio de impacto de la adopción de las nuevas variedades de camote liberadas por el INIA, en la costa central, Perú. Caso del valle de Cañete. Lima, Perú. Centro Internacional de la Papa (CIP), 24 p.

GREGORY, P. (1992). Informe Anual CIP. Centro Internacional de la Papa. Lima.

INEI 1994; 2009; 2012; 2014. Anuario Estadístico Agropecuario. Lima, Perú.

INEI 2010. PERU: Consumo Per cápita de los principales alimentos 2008-2009. Lima.https://www.inei.gob.pe/media/MenuRecursivo/publicaciones_digitales/Est/Lib1028/ cap01.pdf

INIA (2000). Normas para el lanzamiento de nuevo cultivar. (Resolución Jefatural Nº20-2000.INIA-AG). Lima - Perú.

JULCA, I. K. (2014). Producción de camote comercial (Ipomoea batatas (L) Lam) cv. Jonathan con distintos tipos de semilla, densidad y fertilización en costa central. Tesis Ing. Agr. UNA La Molina Lima.

LEÓN-VELARDE, C. y Felipe de Mendiburu. (2003). Seminario "Estrategias para el uso del camote en la alimentación humana y animal". CIP-IICA/ FONTAGRO-BID. Lima, Mayo 29-31, 2003.

LLANOS, R. J. 1994. Influencia del corte de follaje sobre el rendimiento de raíces reservantes en camote (Ipomoea batatas L. Lam) bajo condiciones de costa central-Cañete. Tesis Ing. Agr. UNALM - Perú.

MARTÍ, H. (2003). Desarrollo de productos de camote en la Argentina. INTA Argentina. IN: Resúmenes del Taller, 29-31 mayo 2003. Lima. CIP-FONTAGRO.

MINAG-PIURA. (2000). Plan de Desarrollo ganadero para el departamento de Piura. 2000-2015. Piura-Perú.

MOLINA, J. P. (1994). Expediente Técnico para la Liberación de la Variedad INA 100-INIA, E. E. D'ONOSO INIA. Huaral Lima.

MOLINA, J. P. (2004). Manual del cultivo de camote. INIA Lima Perú.

PAEN/GTZ-CTAR-Piura. (2002). Desarrollo Agropecuario Sostenible y Oportunidades de mercado. Piura-Perú.

QUISPE, C. A. (2005). Validación del nuevo cultivar de camote forrajero Lactogénico. En: Ciencia y Desarrollo 6 (1) 7-30. Revista de la UAP. Lima Perú.

SEVILLA, P. R. (2003). Oficial Secretaria Técnica de Coordinación del CGIAR. MINAG. Comunicación personal. Lima, Perú. 
RABINES, J.L. (1993). Comparativo de rendimiento de cinco clones de camote (Ipomoea batatas (L) Lam.) bajo dos densidades de siembra en condiciones de Costa Central (Cañete). Tesis de Ing. Agrónomo. UNA LA Molina, Perú.

ROCA, T. J., De Mendiburu, F. y León-Velarde, C. U. (2002). Selección de Accesiones de camote (Ipomoea batatas L.) con características de doble propósito. Análisis de evaluaciones agronómicas (1994-2002) La Molina-Lima.
SAAVEDRA, A. J. (1999). Respuesta de clones avanzados de camote (Ipomoea batata (L) Lam), a dos densidades de plantación en costa Central. Tesis. Ing. Agrónomo UNA LA Molina. Lima. Pág. 9-10, 13-25.

SALAS, M. E. (2002). Evaluación de nuevos clones de camote (Ipomoea batatas (L.) Lam) con características promisorias para la costa Central. Tesis UNALM, Lima

VILLAGARCIA, M. (1990). Ecología y Fisiología del cultivo de camote. II Curso Internacional sobre el cultivo de Camote. INTA-CIP. Argentina.

\section{Anexos:}

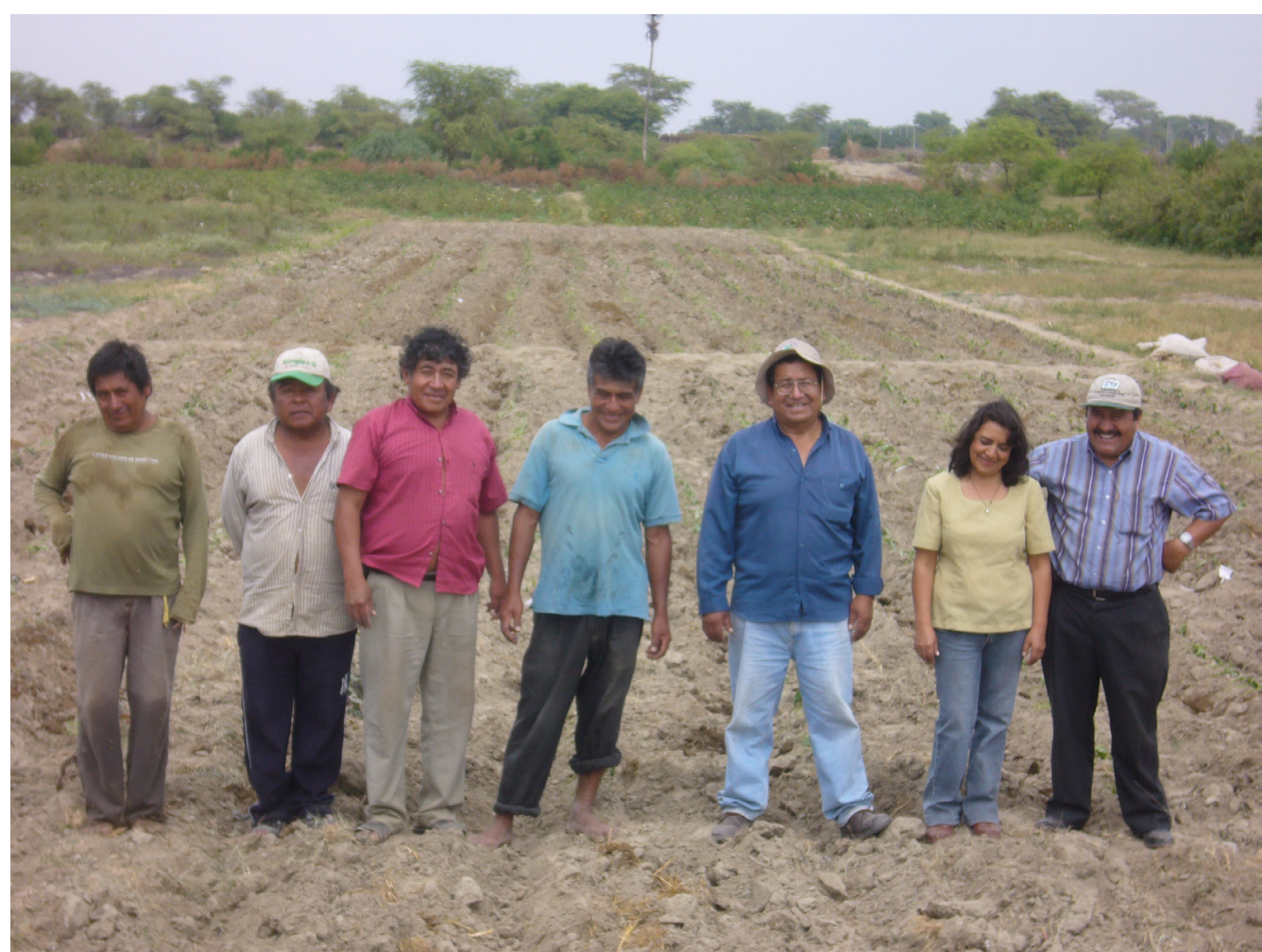

Equipo de profesionales y productores en campo preparado para un ensayo 


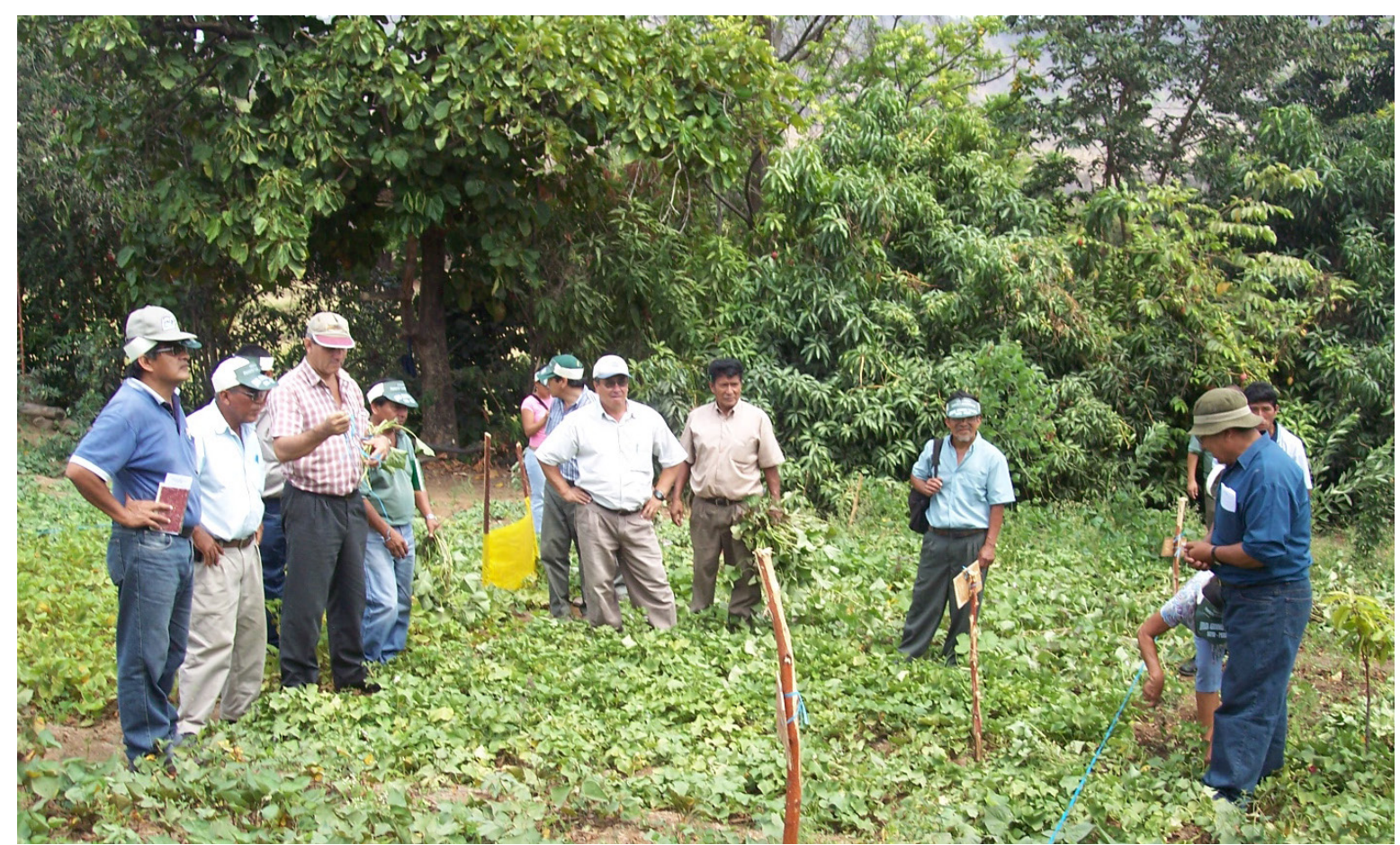

Demostración de las bondades de los clones promisorios de camote de doble propósito

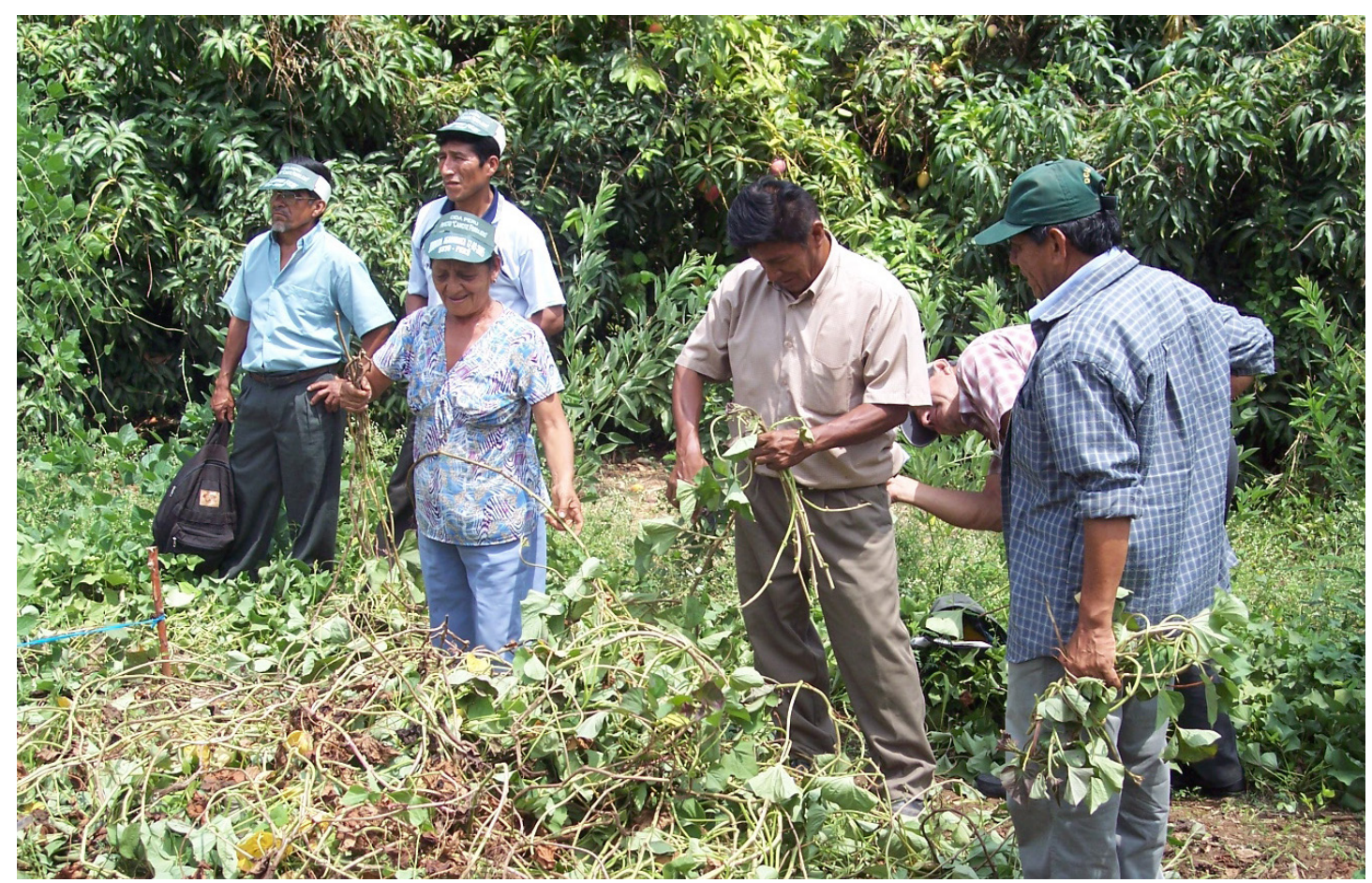

Extracción demostrativa de esquejes-semilla de camote 


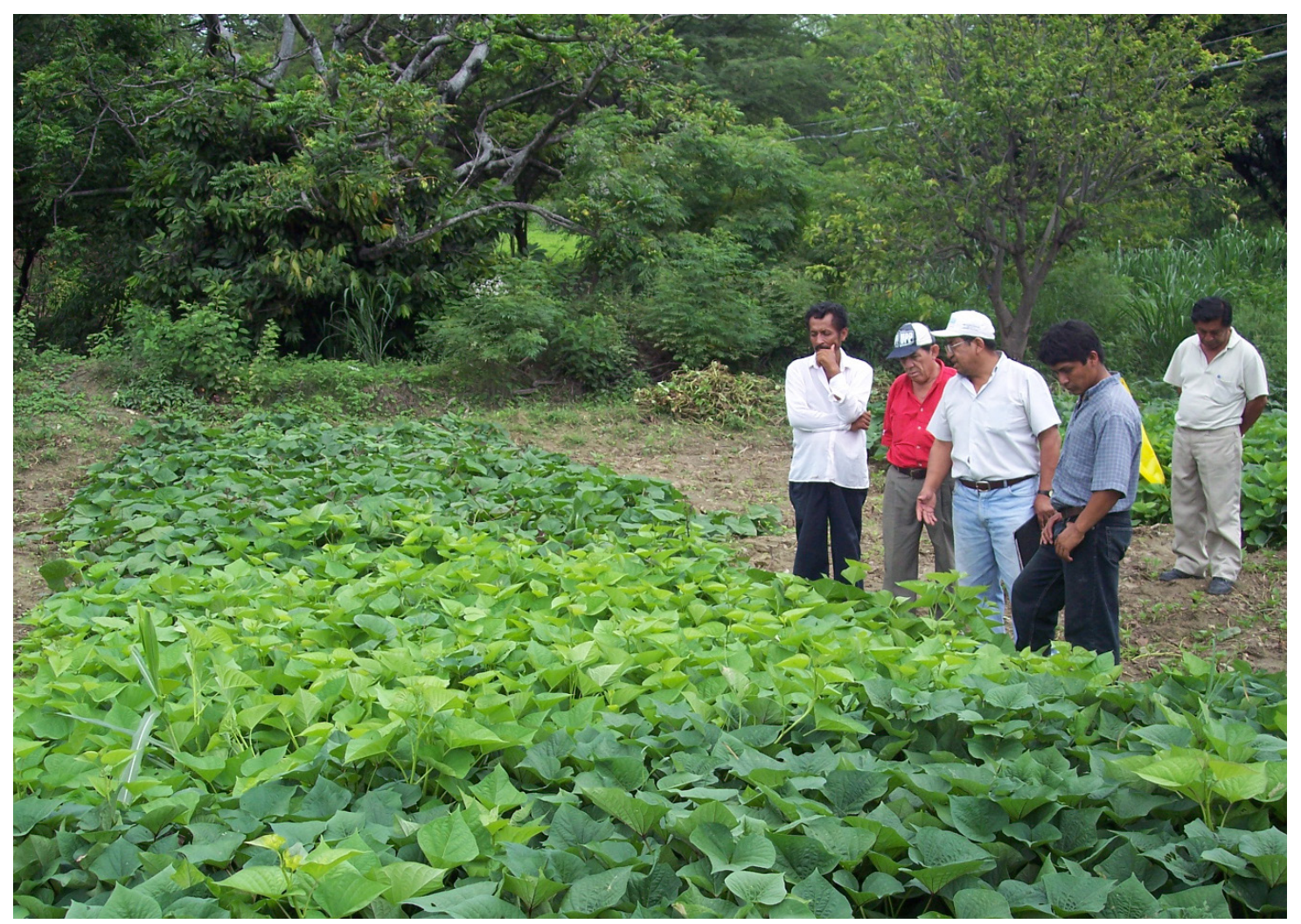

Demostración de los cortes de forraje (Área sin forraje con corte y no cortada con follaje)

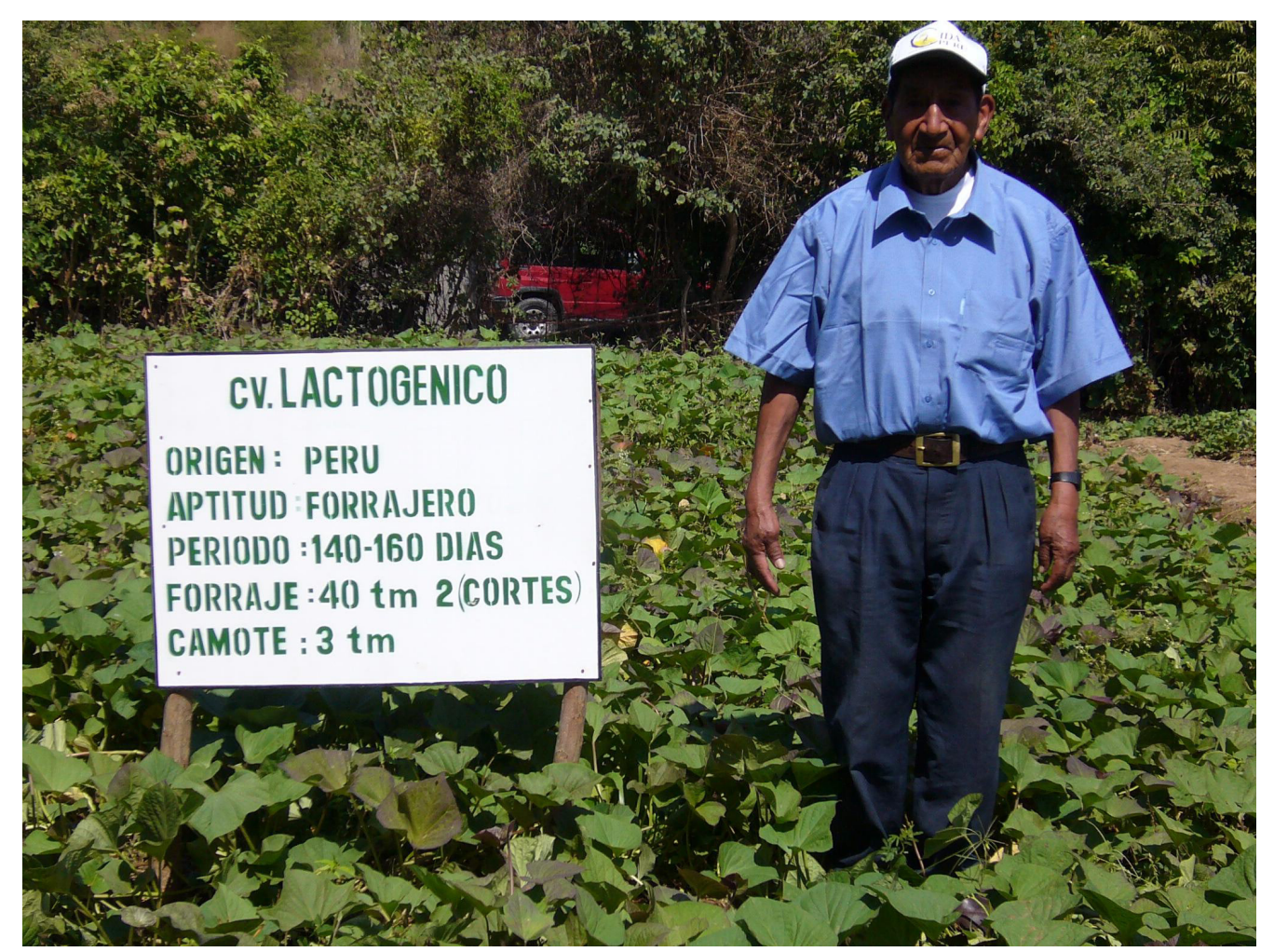

Productor del valle quiroz, con clon "lactogénico" de su preferencia 


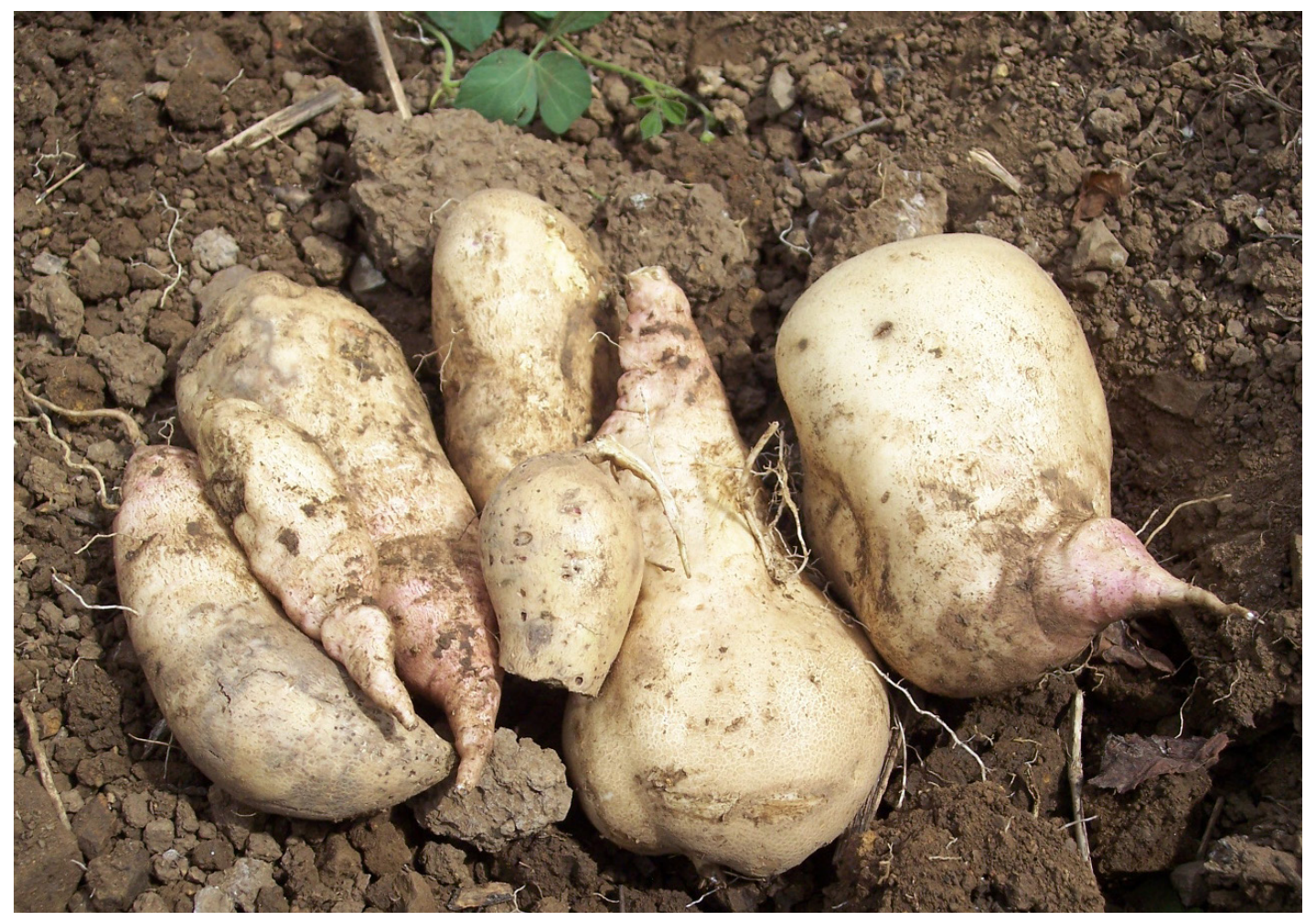

Rendimiento por planta de raíces (camotes)

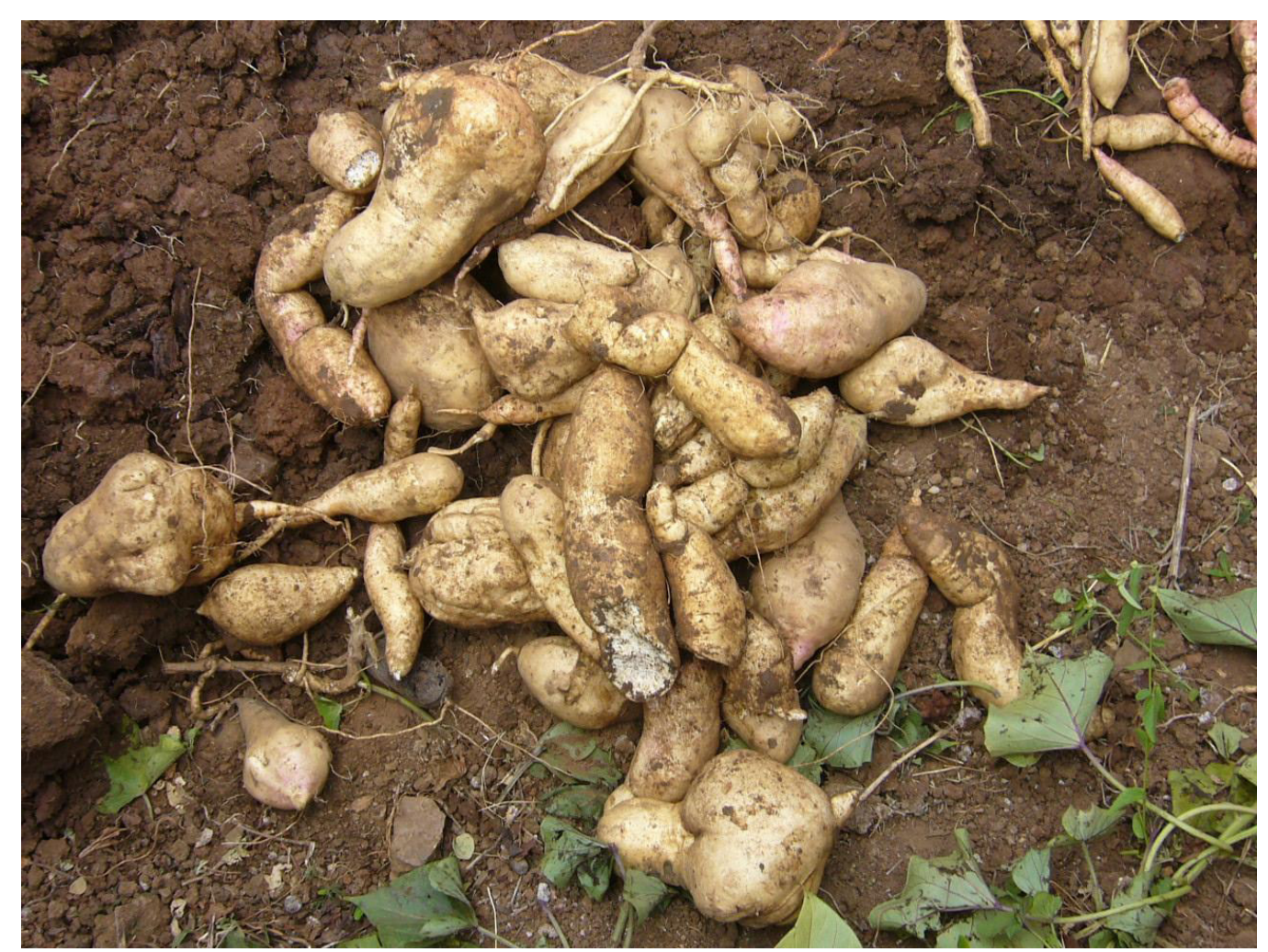

Características de las raíces (camotes) de "toquecita" 


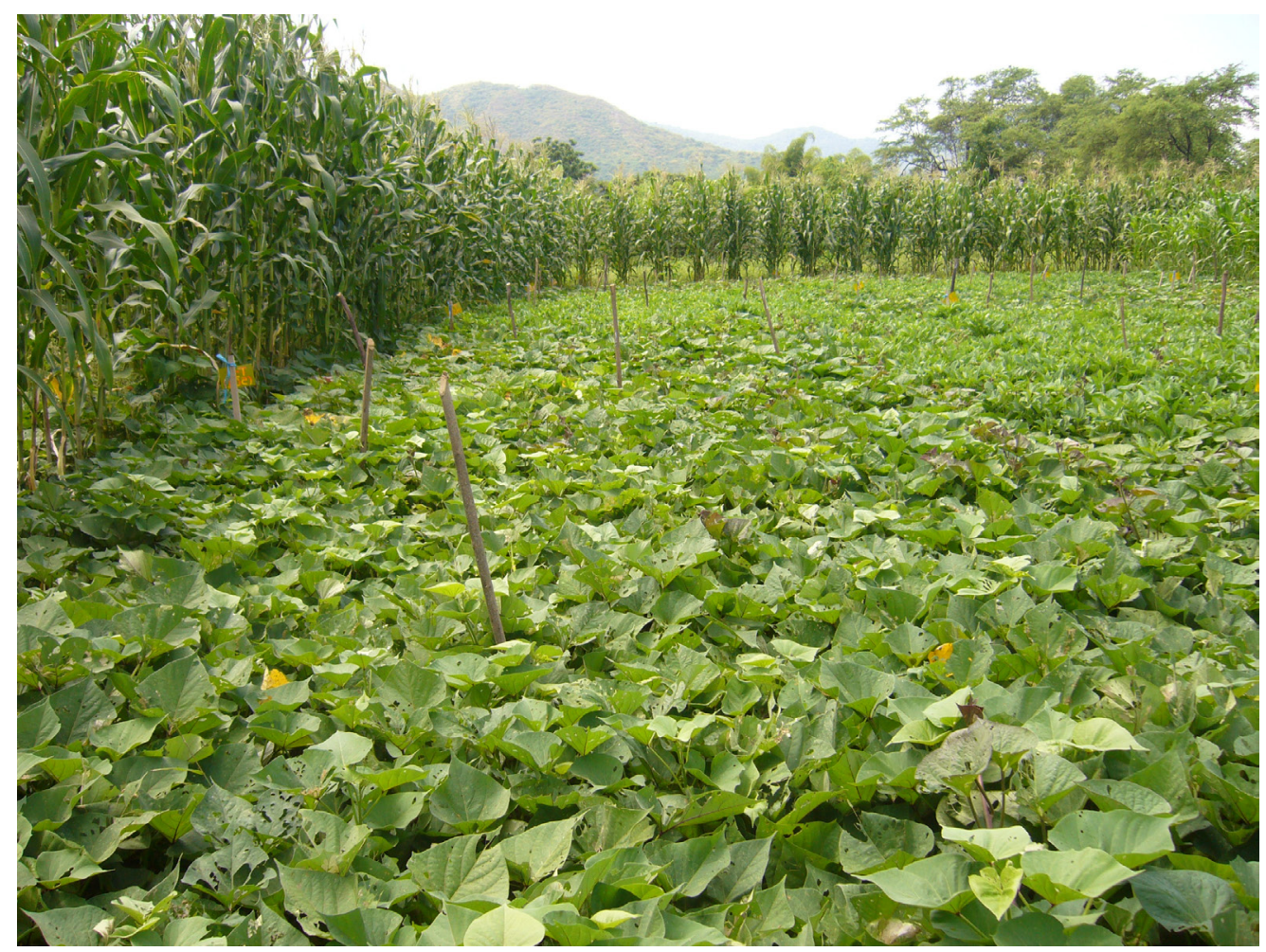

Excelente cultivo de camote "toquecita" en campo comercial. 